\title{
The Structure of Nuclei Far From Stability
}

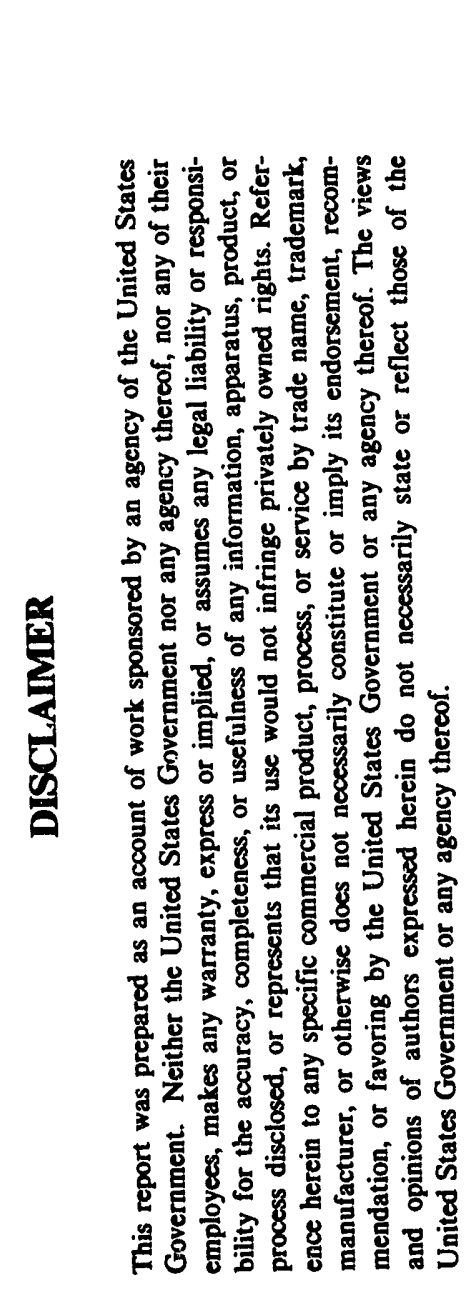

\section{A Progress Report}

E. F. Zganjar

Department of Physics and Astronomy

Louisiana State University

Baton Rouge, Louisiana 70803-4001

For the period

May 15, 1992 to May 14, 1993

RECINVD

MAY 14 is93

OSTI
Prepared for the

U. S. Department of Energy

under

Grant No. DE-FG05-84ER40159 


\section{Table of Contents}

I. Introduction.

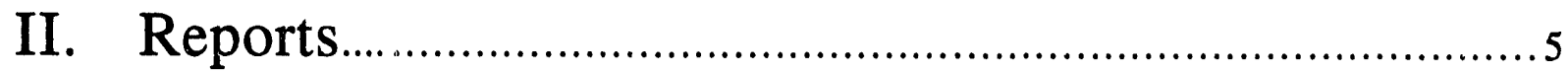

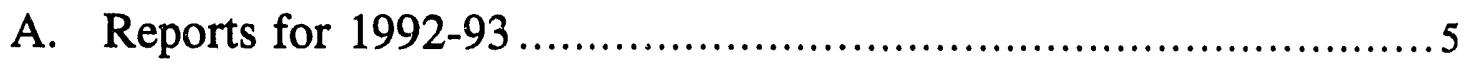

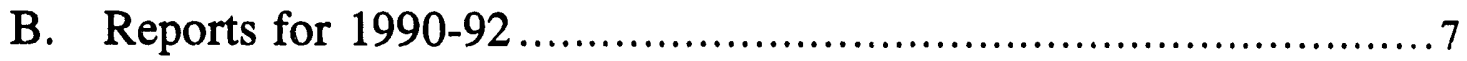

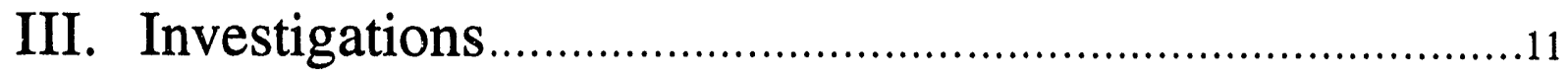

A. Shape Coexistence and Electric Monopole Transitions..................11

1. Pure Electric Monopole Transitions in ${ }^{185} \mathrm{Pt}$.............................. 12

2. Shape Coexistence and Electric Monopoles in ${ }^{184} \mathrm{Pt} \ldots \ldots \ldots \ldots \ldots \ldots \ldots . . \ldots \ldots 13$

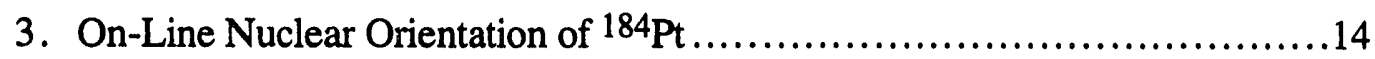

4. Lifetimes of the $0_{2}^{+}$Configuration in ${ }^{186} \mathrm{Hg}$ and ${ }^{188} \mathrm{Hig} \ldots \ldots \ldots \ldots \ldots \ldots . . . \ldots 15$

5. Shape Coexistence and Complete Spectroscopy in ${ }^{187} \mathrm{Au} . \ldots \ldots \ldots \ldots \ldots \ldots . .21$

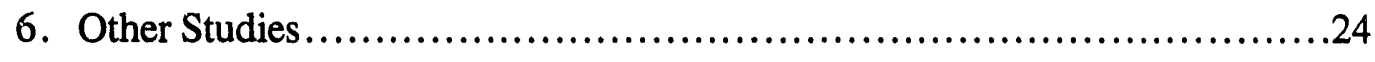

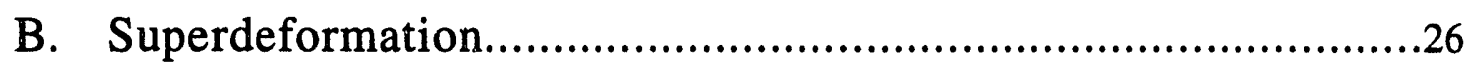

1. Search for Population of Superdeformed States in ${ }^{192} \mathrm{Hg}$ Using ${ }^{192} \mathrm{Tl} \beta^{+}$Decay.......................................................28

2. Search for Population of Superdeformed States in ${ }^{194} \mathrm{~Pb}$ Using ${ }^{194} \mathrm{Bi} \beta+$ Decay .....................................................

C. Other Studies ............................................................ 37

IV. Experimental Developments..............................................39

A. Picosecond Lifetime Measurement Systems for Levels Populated by Electron Capture and for Levels Decaying by E0 transitions.

B. An Internal Pair Spectrometer for High Energy Conversion Electron Spectroscopy 


\section{Introduction}

Our research program is at a crossroads. This report brings to a conclusion our work at UNISOR using stable beams and the UNISOR isotope separator in a mode where we have been able to obtain upwards of $10^{6}$ separated ions/sec. The intensity and quality of beams from the UNISOR isotope separator have enabled us to perform the in-depth type of spectroscopy, particularly coincidence spectroscopy with conversion electrons, for which we have become noted. While a change in the UNISOR phase of this program will take place in the coming years, the spectroscopic expertise developed during the past decade will enable us to make important measurements with significantly lower beam intensities. The prospect of radioactive ion beams and a new state of the art recoil mass spectrometer at the Oak Ridge Radioactive Ion Beam Facility (RIB) will enable us to carry the research to nuclear species even further from stability and, thus, enable us to carry out fundamental nuclear spectroscopic measurements which have been previously impossible. Accompanying with this change will be a significant shift to more in-beam spectroscopy, particularly at the front-end of the recoil mass separator.

This report is written to describe our contribution to nuclear structure physics during the past year. We make no attempt to credit others, and there are many, who have contributed to these same topics. This is done in published papers. Also, the individual sections are often a synopsis of one or more of the 16 reports which have resulted from the 1992-93 period of support. Selected material was extracted (literally) from those papers and reassembled here so that this progress report would read as a single document rather than a collection of reprints.

Our extensive data from studies on nuclei near $Z=82$ has contributed to the establishment of a new region of nuclear deformation and a new class of nuclear structure at closed shells. A most important aspect of this work is the establishment of the connection between low-lying $0^{+}$states in even-even nuclei and the occurrence of shape 
coexistence in the odd-mass neighbors. One of the "tools" developed to probe these structures is the enhancement of the E0 multipole in the transitions connecting the shape coexisting configurations. Recent results along these lines include the observation of six transitions in ${ }^{185} \mathrm{Pt}$ which are essentially pure E0, an unprecedented occurrence in an oddmass nucleus; and the identification of two previously unobserved $\mathrm{K}^{\pi}=2+$ bands of states connected by strong E0 transitions in ${ }^{184} \mathrm{Pt}$.

A direct measure of the mixing of coexisting shapes is the E0 strength between the intruder state and the ground state. To measure this strength, it is necessary to obtaind the half-life of the level decaying by the E0 transition which connects the two configurations. Consequently, during the past year we developed a new type of picosecond lifetime measurement system (described in IV A), capable of measuring the lifetime of states which decay only by internal conversion, and applied it to the $186,188 \mathrm{Tl}$ decay to determine the lifetime of the $0_{2}^{+}$and $2_{2}^{+}$deformed states in $186,188 \mathrm{Hg}$. This lifetime system, designed to be transportable, will be u.sed in several U.S. and European laboratories during the period of RIB development in order to complete our lifetime measurements on the neutrondeficient $\mathrm{Hg}$ and $\mathrm{Pt}$ isotopes. A. quantitative and systematic determination of the mixing of the deformed and more spherical shape coexisting configurations in these nuclei is critical to the proper evolution of the theoretical pictures used to ascertain the mechanisms that give rise to the shape coexistence in the region. Our complete spectroscopy on the structure of odd-mass ${ }^{187} \mathrm{Au}$, the transitional nucleus which bridges deformed and more spherical ground states, is complete and will provide theorists with detailed information on more than 145 levels and 430 transitions which quantify, in detail, the shape coexisting configurations arising from the coupling of particles and holes to the various shape coexisting configurations in ${ }^{186} \mathrm{Pt}$ and ${ }^{188} \mathrm{Hg}$.

During the past year, we conducted a search for the population of superdeformed states in ${ }^{192} \mathrm{Hg}$ by the radioactive decay of ${ }^{192} \mathrm{Tl}$ using the internal pair formation (IPF) process. This was accomplished using a prototype IPF spectrometer which we made by 
re-configuring our existing conversion electron spectrometer systems. As a result of this attempt, we launched a program to design and construct an IPF spectrometer for radioactive decay which optimized the geometry required for a high-efficiency device. This new spectrometer is now operational and is described in the last section of this report (IV B). Its first use will be in an experiment at ISOLDE/CERN to search for the population of superdeformed states in ${ }^{198} \mathrm{Po}$ and ${ }^{194} \mathrm{~Pb}$ using the ${ }^{198} \mathrm{At} \stackrel{\beta}{\longrightarrow} 198 \mathrm{Po} \stackrel{\alpha}{\longrightarrow}{ }^{194} \mathrm{~Pb}$ decay. Apart from these types of searches, the IPF spectrometer has a great future as a multipole meter for high energy transitions. It is also the best type of spectrometer for high-energy E0 spectroscopy.

While it is a long shot that $\beta$ decay will populate superdeformed states due to the great dissimilarity between the parent ground state and daughter superdeformed state, and also due to the uncertainty associated with the available decay energy (the location of the superdeformed states are unknown experimentally), it is nonetheless important to make the attempt since a successful experiment would enable one to pin down the energy of the superdeformed state with absolute certainty. Our superdeformation searches using the internal pair formation process to look for high-energy E0 transitions, and the internal conversion process to observe the very low-energy superdeformed intraband transitions through electron-electron correlations (section III B), will enable us to set the most severe limits to date on the population of superdeformed states in the ${ }^{192} \mathrm{Tl}$ decay. The search to be conducted at ISOLDE/CERN on the decay of several Po isotopes from At decay is probably the best case in terms of parent/daughter states and transition Q-values. While this experiment involves an extensive collaboration and other leadership, it will utilize our new IPF spectrometer and involve one of the LSU graduate students.

We have attempted to keep our research on the structure of nuclei far from stability at the cutting edge of important physics and have constructed a number of unique spectroscopic tools, in addition to developing a variety of innovative experimental approaches, to accomplish that objective. We intend to continue this approach and look 
forward to even more challenges as we assist in the development of spectroscopy, spectroscopic techniques, and spectroscopic instruments using radioactive ion beams and a state-of-the-art recoil mass separator. 


\section{Reports}

\section{A. Reports for 1992-93}

Listed below are the reports, papers, and abstracts that have emerged during the final year of the three year award (May 15, 1992 - January 15, 1993) under U. S. Department of Energy grant DE-FG05-84ER40159.

DOE/ER/40159-180 "Pure Electric Monopole Transitions in an Odd-Mass Nucleus," J. Schwarzenberg, J.L. Wood, and E.F. Zganjar, Phys. Rev. C45 R896 (1992).

DOE/ER/40159-184 "Detailed Nuclear Structure Studies Far From Stability," J.L. Wood, J.Schwarzenberg, E.F. Zganjar, and D. Rupnik, Proceedings of the Second International Conference on On-Line Nuclear Orientation and Related Topics, Oak Ridge, Tennessee, October 16-19, 1991, Hyp. Int. 75, 51 (1992).

DOE/ER/40159-185 "On-Line Nuclear Orientation Study of ${ }^{184} \mathrm{Au}, "$ Y. Xu, K.S. Krane, M.A. Gummin, J.L. Wood, M.M. Jarrio, J.B. Breitenbach, E.F. Zganjar, D. Rupnik, H.K. Carter, P.F. Mantica, Jr., and B.E. Zimmerman, Proceedings of the Second International Conference on On-Line Nuclear Orientation and Related Topics, Oak Ridge, Tennessee, October 16-19, 1991, Hyp. Int. 75, 441 (1992).

DOE/ER/40159-186

"The Electric Monopole Transition: Nuclear Structure and Nuclear Spectroscopy," E.F. Zganjar, Invited Paper, ACS meeting in Washington, D.C., August 23-28, 1992.

DOE/ER/40159-187 "Search for Population of Superdeformed States in ${ }^{194} \mathrm{~Pb}$ Using ${ }^{194} \mathrm{Bi}$ $\beta+$ Decay," M.A. Stoyer, E.A. Henry, J.A. Becker, R.W. Hoff, A. Kuhnert, T.F. Wang, J. Breitenbach, M. Jarrio, J.L. Wood, Y.A. Akovali, C.R. Bingham, M. Zhang, P. Joshi, H.K. Carter, J. Kormicki, and P. Mantica, presented at the International Conference on Nuclear Structure at High Angular Momentum, Ottawa, Canada, May 18-21, 1992.

DOE/ER/40159-188 "Decay of Mass-Separated ${ }^{199} \mathrm{Bi}$ : Nuclear Structure of ${ }^{199} \mathrm{~Pb}$ ", $\mathrm{M}$. Zhang, C.R. Bingham, J. Ding, B.E. Zimmerman, H.K. Carter, J. Kormicki, P. Mantica, L. Rayburn, P. Joshi, J.L. Wood, and S. Sastry, Bull. Am. Phys. Soc. 37, 1321 (1992).

DOE/ER/40159-189

"Shape Coexistence and Electric Monopole Transitions in ${ }^{184} \mathrm{Pt}$," Y. Xu, K.S. Krane, M.A. Gummin, M. Jarrio, J.L. Wood, E.F. Zganjar, and H.K. Carter, Phys. Rev. Lett. 68, 3853 (1992). 
DOE/ER/40159-190

DOE/ER/40159-191

DOE/ER/40159-192

DOE/ER/40159-193

DOE/ER/40159-194

DOE/ER/40159-195

DOE/ER/40159-196
"Search for Population of Superdeformed States in ${ }^{194} \mathrm{~Pb}$ Using ${ }^{194} \mathrm{Bi}$ $\beta^{+}$Decay," M.A. Stoyer, E.A. Henry, Y.A. Akovali, J.A. Becker, C.R. Bingham, J. Breitenbach, H.K. Carter, R.W. Hoff, M. Jarrio, P. Joshi, J. Kormicki, A. Kuhnert, P.F. Mantica, T.F. Want, J.L. Wood, and M. Zhang, Phys. Rev. C (in press).

"Lifetime Measurements in ${ }^{120}$ Xe," P.F. Mantica, P.K. Joshi, S.J. Robinson, E.F. Zganjar, R.L. Gill, W.B. Walters, D. Rupnik, H.K. Carter, J. Kormicki, and C.R. Bingham, The 6th International Conference on Nuclei Far from Stability \& the 9th International Conference on Atomic Masses and Fundarnental Constants, July 19-24, 1992, Bernkastel-Kues, Germany (abstract and proceedings, in press).

"Lifetime of the $0_{2}^{+}$Configuration in ${ }^{188} \mathrm{Hg}$," P.K. Joshi, P.F. Mantica, S.J. Robinson, E.F. Zganjar, R.L. Gill, H.K. Carter, J. Kormicki, D. Rupnik, W.B. Walters, and C.R. Bingham, The 6th International Conference on Nuclei Far from Stability \& the 9th International Conference on Atomic Masses and Fundamental Constants, July 19-24, 1992, Bernkastel-Kues, Germany (abstract).

"Lifetimes of the $0_{2}^{+}$Configurations in ${ }^{186} \mathrm{Hg}$ and ${ }^{188} \mathrm{Hg}$," P.K. Joshi, P.F. Mantica, S.J. Robinson, E.F. Zganjar, R.L. Gill, H.K. Carter, J. Kormicki, D. Rupnik, W.B. Walters, and C.R. Bingham, The 6th International Conference on Nuclei Far from Stability \& 9th International Conference on Atomic Masses and Fundamental Constants, July 19-24, 1992, Bernkastel-Kues, Germany (proceedings, in press).

"Search for Population of Superdeformed States in ${ }^{194}$ Bi $\beta^{+}$-Decay," M.A. Stoyer, E.A. Henry, J.A Becker, R.W. Hoff, A. Kuhnert, D. Manatt, T.F. Wang, J. Breitenbach, M. Jarrio, J.L. Wood, Y.A. Akovali, C.R. Bingham, M. Zhang, P.K. Joshi, H.K. Carter, J. Kormicki, and P. Mantica, 203rd American Ciemical Society National Meeting, April 5-10, 1992, San Francisco, California (in press).

"Search for the Population of the ${ }^{194} \mathrm{~Pb}$ Superdeformed Band by Beta Decay," M.A. Stoyer, J.A. Becker, E.A. Henry, R.W. Hoff, T.F. Wang, J.L. Wood, M. Jarrio, J. Breitenbach, Y.A. Akovoli, H.K. Carter, P. Mantica, J. Kormicki, C.R. Bingham, M. Zhang, and P. Joshi, Bull. Am. Phys. Soc. (late).

"Search for Low-Spin Superdeformed States in Nuclei," C.R. Bingham, M. Zhang, J.A. Becker, E.A. Henry, R.W. Hoff, A. Kuhnert, M.A. Stoyer, T.F.Wang, Y.A. Akovali, P. Joshi, T.S. Lam, D. Rupnik, E.F. Zganjar, J. Breitenbach, M. Jarrio, J.L. Wood, H.K. Carter, P.F. Mantica, Jr., and J. Kormicki, 12th International Conference on the Application of Accelerators in Research and Industry, Denton, Texas, November 2-4, 1992 (in press). 
DOE/ER/40159-197 "Lifetimes of the $0_{1}^{+}$Configuration in $186 \mathrm{Hg}$ and ${ }^{188} \mathrm{Hg}$," P.K. Joshi, E.F. Zganjar, D. Rupnik, S.J. Robinson, P.F. Mantica, H.K. Carter, R.L. Gill, W.B. Walters, C.R. Bingham, J. Kormicki, A.V. Ramayya, W.C. Ma, and J.H. Hamilton, preprint, submitted to Phys. Rev. C.

DOE/ER/40159-198 "Picosecond Lifetime Measurement Systems for Levels populated by Electron Capture and for Levels Decaying by E0 Transitions," P.K. Joshi, E.F. Zganjar, S.J. Robinson, and P.F. Mantica, preprint, submitted to Nucl. Inst. Meth.

DOE/ER/40159-199 "Progress Report", E.F. Zganjar, report cn research under DEFG0584ER40159 for the period May 15, 1992, to May 14, 1993.

\section{B. Reports for $1990-92$}

Listed below are the reports, papers, and abstracts which emerged during the initial period of support (May 15, 1990 - May 14, 1992) under U. S. Department of Energy grant DE-FG05-84ER40159. These are included here for completeness since this report is the last annual report for the three-year award.

DOE/ER/40159-156 "Decay of Mass Separated 193 Tl: Interpretation Based on a ParticleCore Coupling Model," H.V. Carmichael, C.R. Bingham, L.L. Riedinger, P.B. Semmes, H.K. Carter, E.F. Zganjar, M.O. Kortelahti, and J.L. Wood, Bull. Am. Phys. Soc. 35, 1016 (1990).

DOE/ER/40159-157 "On-Line Nuclear Orientation of ${ }^{184} \mathrm{Au}, "$ Y.S. Xu, K.S. Krane, M.A. Gummin, J.T. Elliott, H.K. Carter, I.C. Girit, D.Rupnik, E.F. Zganjar, J.L. Wood, P.F. Mantica, Jr., and B.E. Zimmerman, Bull. Am. Phys. Soc. 35, 1657 (1990).

DOE/ER/40159-158 "Weak Coupling in the Odd-Mass Xe Nuclides: Decay of $6.2 \mathrm{~h}{ }^{127} \mathrm{Cs}$ to Levels of Odd-Neutron ${ }^{127}$ Xe," P.F. Mantica, Jr., B.E. Zimmerman, W.B. Walters, H.K. Carter, D. Rupnik, E.F. Zganjar, W.L. Croft, and Y.S. Xu, Phys. Rev. C42, 902 (1990).

DOE/ER/40159-159 "The Level Structures of ${ }^{119} \mathrm{Te}$ and ${ }^{121} \mathrm{Te}$ Populated in the Decay of ${ }^{119} \mathrm{I}$ and ${ }^{121} \mathrm{I}, "$ P.F. Mantica, Jr., B.E. Zimmerman, W.B. Walters, D. Rupnik, E.F. Zganjar, J. Kormicki, W.D. Schmidt-Ott, and H.K. Carter, Phys. Rev. C42, 1312 (1990).

DOE/ER/40159-160 "Electric Monopole Transitions and Shape Coexistence in Nuclei," E.F. Zganjar and J.L: Wood, abstract of paper presented at the Conference on Nuclear Structure in the Nineties, April 23-27, 1990 Oak Ridge, Tennessee. 
DOE/ER/40159-161

DOE/ER/40159-162

DOE/ER/40159-163

DOE/ER/40159-165

DOE/ER/40159-166

DOE/ER/40159-167

DOE/ER/40159-168

DOE/ER/40159-169

DOE/ER/40159-170

DOE/ER/40159-171
"Transitional Nuclei in the Rare-Earth Region: Energy Levels and Structure of $130,132 \mathrm{Ce}, 132,134 \mathrm{Nd}$, and ${ }^{134} \mathrm{Pm}$, via $\beta$ Decay of ${ }^{130,134} \mathrm{Pm}$, and ${ }^{134} \mathrm{Sm}, "$ M.O. Kortelahti, B.D. Kern, R.A. Braga, R.W. Fink, I.C. Girit and R.L. Mlekodaj, Phys. Rev. C42, 1267 (1990).

"Identification of Transitions in ${ }^{73} \mathrm{Kr}$ and the Search for Large Oblate Deformation," M. Satteson, A.V. Ramayya, T.M. Cormier, H.E. Gove, L. Chaturvedi, X. Zhao, J. Kormicki, J.H. Hamilton, E.F. Zganjar, I.Y. Lee, C. Baktash, F.K. McGowan, N.R. Johnson, J.D. Cole, and H. Dejbakhsh, J. Phys. G16, L27 (1990).

"Intruder States, Coexistence, and Approaches to Deformation: The Study of $120 \mathrm{Xe}$ and the $\mathrm{N}=66$ Isotones," P.F. Mantica, Jr., B.E. Zimmerman, C.E. Ford, W.B. Walters, D. Rupnik, E.F. Zganjar, H.K. Carter, J. Rikovska, and N.J. Stone, Exotic Nuclear Spectrosopy, ed. W. C. McHarris (Plenum Press, New York, 1990), p. 495.

"Spectroscopic Techniques in the Study of Radioactive Nuclei Far From Stability: Results for the Z=82 Region," E.F. Zganjar, J.L. Wood, and J. Schwarzenberg, Exotic Nuclear Spectroscopy, ed. W.C. McHarris (Plenum Press, New York, 1990), p.39.

"Electric Monopole Transitions and Shape Coexistence in Nuclei," E.F. Zganjar and J.L. Wood, Nucl. Phys. A520, 427c (1990).

"The Electric Monopole Transition in Nuclei," E.F. Zganjar, Invited paper, Symposium on Recent Advances in Nuclear Structure Research, American Chemical Society Meeting, Atlanta, Georgia, April 14-19, 1991.

"Structure of Even-Even and Even-Odd Xe Nuclides," P.F. Mantica, Jr., H.K. Carter, B.E. Zimmerman, W.B. Walters, J. Rikovska, N.J. Stone, D. Rupnik, and E.F. Zganjar, submitted for presentation at the American Chemical Society Meeting, Atlanta, Georgia, April 14-19, 1991.

"Single-particle States in the Rare Earth Region Near the Proton Drip Line," K.S. Toth, D.C. Sousa, J.M. Nitschke, K.S. Vierinen, P.A. Wilmarth and M.O. Kortelahti, (preprint--not submitted for publication).

"Spectroscopy of Proton-Rich Nuclei in the Rare Earth Region," K.S. Toth, J.M. Nitschke, K.S. Vierinen, P.A. Wilmarth, R.B. Firestone, and M.O. Kortelahti, Nuclear Instruments and Methods in Physics Research B 56/57, 484 (1991).

"Shape Coexistence in $190 \mathrm{Hg}$," M.O. Kortelahti, E.F. Zganjar, J.L. Wood, C.R. Bingham, H.K. Carter, K.S. Toth, J.H. Hamilton, J. Kormicki, L. Chaturvedi, and W.B. Newbolt, Physical Review C43, 484 (1991). 
DOE/ER/40159-172 "New Insights from Theory and Experiment into the Multiple Band Structures and Unusually Large Deformations in $68 \mathrm{Ge}$ and $72 \mathrm{Se}$," L. Chaturvedi, X. Zhao, A.V. Ramayya, J.H. Hamilton, J. Kormicki, C. Girit, H. Xie, Y.-R. Jiang, W.-B. Gao, A. Petrovici, K.W. Schmid, A. Faessler, N.R. Johnson, C. Backtash, I.Y. Lee, F.K. McGowan, M.A. Riley, J.H. McNeill, M.O. Kortelahti, H.Q. Jin, and R.B. Piercey, presented at the Nuclear Structure in the Nineties conference, Vol. 1 of the proceedings, April 23-27, 1990, Oak Ridge, Tennessee p. 80.

DOE/ER/40159-173 "Test of Microscopic Calculation of Multiple Band Structures and Large Deformations in $68 \mathrm{Ge}$ and $72 \mathrm{Se}, " \mathrm{~L}$. Chaturvedi, X. Zhao, A.V. Ramayya, J.H. Hamilton, J. Kormicki, S. Zhu, C. Girit, H. Xie, W.B. Gao, J.-R. Jiang, A. Petrovicki, K.W. Schmid, A. Faissler, N.R. Johnson, C. Baktash, I.Y. Lee, F.K. McGowan, M.L. Halbert, M.A. Riley, J.H. McNeill, M.O. Kortelahti, J.D. Cole, R.B. Piercy, and H.Q. Jin, Phys. Rev. C43, 2541 (1991).

DOE/ER/40159-174 "Progress Report," E.F. Zganjar, report on research under DE-FG0j84ER40159 for the period May 15, 1990, to May 14, 1991.

$D O E / E R / 40159-175$ "Investigation of $A=155$ and $A=151$ Nuclides: Identification of the ${ }^{155} \mathrm{Tm} \mathrm{s}_{1 / 2}$ Isomer and of the $155 \mathrm{Yb}$ B Decay Branch", K.S. Toth, K.S. Vierinem, M.O. Kortelahti, D.C. Sousa, J.M. Nitschke, and P.A. Wilmarth, Phys. Rev. C44, 1868 (1991).

DOE/ER/40159-176 "On-Line Nuclear Orientation Study of ${ }^{184} \mathrm{Au}$," Y. Xu, K.S. Krane, M.A. Gummin, J.L. Wood, M.M. Jarrio, J.B. Breitenbach, E.F. Zganjar, D. Rupnik, H.K. Carter, P.F. Mantica, and B.E. Zimmerman, Second International Conference on On-Line Nuclear Orientation and Related Topics, Oak Ridge, Tennessee, October 16-19, 1991, (abstract).

DOE/ER/40159-177 "Nuclear Structure Studies of 187Ir via On-Line Nuclear Orientation," M.A. Gummin, K.S. Krane, Y. Xu, T. Lam, E.F. Zganjar, J.B. Breitenbach, B.E. Zimmerman, P.F. Mantica, and H.K. Carter, Second International Conference on On-Line Nuclear Orientation and Related Topics, Oak Ridge, TN, October 16-19, 1991, (abstract).

DOE/ER/40159-178 "Detailed Nuclear Structure Studies Far From Stability," J.L. Wood, J. Schwarzenberg, E.F. Zganjar, and D. Rupnik, Second International Conference on On-Line Nuclear Orientation and Related Topics, Oak Ridge, TN, October 16-19, 1991, (abstract).

DOE/ER/40159-179 "The History of UNISOR: 1971-1991", Invited paper, Symposium on Reflections and Directions in Low Energy Heavy Ion Physics, Oak Ridge, Tennessee, October 14-15 (1991).

DOE/ER/40159-181 Master's Thesis, Louisiana State University, T. Lam, 1991.

DOE/ER/40159-182 "Progress Report," E.F. Zganjar, report on research under DEFG0584ER40159 for the period May 15, 1991 to May 14, 1992. 
DOE/ER/40159-183 "High Spin States in ${ }^{65} \mathrm{Ga},{ }^{67} \mathrm{Ga}$ and their Collective Behavior at High Angular Momenta," Z. Shergjiang, L. Claturvedi, J.H. Hamilton, A.V. Ramayya, C. Girit, J. Kormicki, X.W. Zhao, W.B. Gao, N.R. Johnson, I.Y. Lee, C. Backtash, F.K. McGowan, M.L. Halbert, M. Riley, M.O. Kortelahti, and J.D. Cole, Chinese Journal of Nuclear Physics, 13, 331 (1991). 


\section{Investigations}

\section{A. Shape Coexistence and Electric Monopole Transitions}

Shape coexistence has become a topic of widespread interest in recent years. Following reviews 1,2 of the topic some years ago, considerable progress had been made in understanding the relationship between intruder states and shape coexistence and in mapping the systematic features of these structures in nuclei, 3,4 Two major qualitative characteristics have now clearly emerged. Shape coexisting bands intrude to become low-lying states in nuclei where one kind of nucleon is at or near a close shell (subshell) and the other kind of nucleon is near mid-shell; and the intruding bands mix only weakly with neighboring states. A dramatic example occurs in the neutron deficient $\mathrm{Hg}(\mathrm{Z}=80)$ isotopes where weakly deformed oblate and strongly deformed prolate shapes coexist at low energy. 2,5

The emission of a $\gamma$ ray in the transition between two nuclear states that both have zero spin and even parity $\left(0^{+}\right)$is forbidden since the photon must carry away one unit of angular momentum. The transition may proceed, however, by internal conversion or internal pair formation through the interaction of an atomic electron with the charge distribution within the confines of the nuclear volume. Sometimes higher-lying $0^{+}$states decay by E0 transitions to the $0^{+}$ground state in competition with E2 decay to the first excited $2^{+}$state. Occasionally an excited state with non-zero spin will undergo a $\Delta \mathrm{J}=0, \Delta \pi=$ no transition to a lower state by a transition with M1 and/or E2 admixed multipolarities. ${ }^{6}$ In odd-mass nuclei, E0 components in $\Delta \mathrm{J}=0, \Delta \pi=$ no transitions are extremely rare.7,8 A major change in this picture has occurred as a result of studies of nuclear shape coexistence where a significant enhancement of the E0 strength has been observed in the $\mathrm{J} \pi \rightarrow \mathrm{J} \pi$ transitions between the shape coexisting configurations. We have discovered six $\Delta \mathrm{J}=0, \Delta \pi=$ no transitions in ${ }^{185} \mathrm{Pt}$ for which we observe only internal conversion (i.e. essentially pure E0 transitions). This is unprecedented. In ${ }^{184} \mathrm{Pt}$ we have observed a completely new feature: In addition to two bands of states with $\mathrm{I}^{\pi}$ $=0^{+}, 2^{+}, 4^{+}, 6^{+}\left(K^{\pi}=0^{+}\right.$bands $)$, we observe two bands of states with $I^{\pi}=2^{+}, 3^{+}, 4^{+}\left(K^{\pi}=\right.$ 
$2^{+}$bands) that are connected by strong E0 transitions. The association of E0 transitions with shape coexistence is well recognized ${ }_{9}^{9}$ but has previously been established only in the case of $\mathrm{K}^{\pi}=0^{+}$bands. These data show that $\mathrm{E} 0$ transitions are also associated with coexistence of $\mathrm{K}^{\pi}$ $=2^{+}$bands.

${ }^{1}$ K. Heyde, P. Van Isacker, M. Waroquier, J.L. Wood, and R.A. Meyer, Phys. Repts. 102, 291 (1983).

2J.H. Hamilton, P.G. Hansen, and E.F. Zganjar, Repts. Prog. Phys. 48, 631 (1985).

${ }^{3}$ K. Heyde, J. Jolie, J. Moreau, J. Ryckebusch, M. Waroquier, P. Van Duppen, M. Huyse, and J.L. Wood, Nucl. Phys. A466, 189 (1987).

${ }^{4}$ K. Heyde et al., Nucl. Phys. A484, 275 (1988).

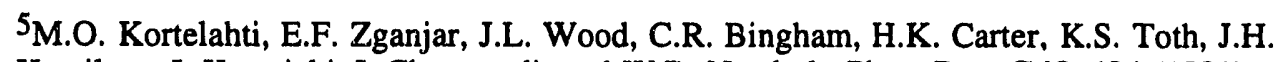
Hamilton, J. Kormicki, L.Chaturvedi, and W.B. Newbolt, Phys. Rev. C43, 484 (1991).

6J. Lange, K. Kumar, and J.H. Hamilton, Rev. Mod. Phys. 54, 119 (1982).

${ }^{7}$ See for example, E.F. Zganjar and J.L. Wood, in Nuclear Structure in the Zirconium Region. proceedings of the International Workshop, Bad Honef, Germany, 1988, J. Eberth et al., eds., Springer Verlag, Berlin, Germany, 1988, p. 88.

${ }^{8}$ See for example, C.D. Papanicolopulos, M.A. Grimm, J.L. Wood, E.F. Zganjar, M.O.

Kortelahti, J.D. Cole, and H.K. Carter, Z. Phys. A330, 371 (1988).

${ }^{9}$ Many references, but see, for example, E.F. Zganjar, and J.L. Wood, Nucl. Phys. A520, $427 c(1990)$.

\section{Pure Electric Monopole Transitions in ${ }^{185} \mathrm{Pt}$.}

We have studied excited states in ${ }^{185} \mathrm{Pt}$ through the radioactive decay of massseparated ${ }^{185} \mathrm{Au}\left(6.8 \mathrm{~m}, \mathrm{~J}^{\pi}=5 / 2^{-}\right)$by using the UNISOR isotope separator. The activity was produced by the $\left({ }^{12} \mathrm{C}, 8 \mathrm{n}\right)$ reaction on a ${ }^{181} \mathrm{Ta}$ target using $140 \mathrm{MeV}{ }^{12} \mathrm{C}$ ions. Gamma-ray and conversion-electron spectrum multiscaling and $\gamma-\gamma-t, \gamma-x-t, \gamma-e-t$, and e-x-t coincidence measurements were conducted on line. Conversion-electron spectra were taken with a $200 \mathrm{~mm}^{2} \times 3 \mathrm{~mm}$ cooled $\mathrm{Si}(\mathrm{Li})$ detector. All assignments of $\gamma$ ray and internally converted transitions were made on the basis of coincidence information. Eleven transitions with EO admixture were observed and for six of those no corresponding $\gamma$-ray intensity was detected, implying essentially pure E0 transitions between states of similar spin/parity but for which $\mathrm{J} \neq 0$. This is unprecedented. 
Although the absence of observable $\gamma$-decay strength in the reported E0 transitions is surprising, the occurrence of EO strength in ${ }^{185} \mathrm{Pt}$ is not surprising. Electric monopole strength is expected ${ }^{1}$ whenever configurations with different mean-square charge radii $\left\langle r^{2}\right\rangle$ mix. There is extensive evidence that states with different deformation, and therefore different $\left\langle\mathrm{r}^{2}\right\rangle$, occur in ${ }^{185,187} \mathrm{Pt}$. This is supported by energy-level systematics, ${ }^{2} \mathrm{E} 2$ transition probabilities, ${ }^{2,3}$ and isotope shifts ${ }^{4}\left(\delta<\mathrm{r}^{2}>\right)$. We interpret the E0 transitions observed in this work as resulting from the mixing of low-lying, strongly deformed configurations and higher-lying, weakly deformed configurations. See DOE/ER/40159180 for more details.

\footnotetext{
${ }^{1}$ K. Heyde and R.A. Meyer, Phys. Rev. C37, 2170 (1988); J. Kantele, in Heavy Ions and Nuclear Structure, Proceedings of the Fourteenth Summer School, Mikolajki, Poland, 1984, B. Sikora and Z. Wilhelmi Harwood Academic, New York, 1984, p. 391.

${ }^{2}$ See, e.g., G.D. Dracoulis et al., J. Phys. G12, 297 (1986); B. Cederwall et al., Z. Phys. A337, 283 (1990).

${ }^{3}$ U. Garg et al., Phys. Lett. B180, 319 (1986).

${ }^{4}$ H.T. Duong et al., Phys. Lett. B217, 401 (1989); T. Hilberath et al., Z. Phys. A332, 107 (1989).
}

\section{Shape Coexistence and Electric Monopole Transitions in ${ }^{184} \mathbf{P t}$}

Excited states of ${ }^{184} \mathrm{Pt}$ were studied through the radioactive decay of mass-separated ${ }^{184} \mathrm{Au}\left(\mathrm{t}_{1 / 2}=53 \mathrm{~s}, \mathrm{I}=6\right)$ by using the UNISOR isotope separator ${ }^{1}$ operated on line to the 25-MV tandem accelerator at Holifield. The ${ }^{184} \mathrm{Au}$ was produced through the $\left({ }^{12} \mathrm{C}, 9 \mathrm{n}\right)$ reaction on a target of ${ }^{181} \mathrm{Ta}$ using a beam of $140-\mathrm{MeV}{ }^{12} \mathrm{C}$ ions. Gamma-ray and conversion-electron spectrum multiscaling and $\gamma-\gamma-t$, and $\gamma-x-t, \gamma-e-t$, and $\mathrm{e}-\mathrm{x}-\mathrm{t}$ coincidence measurements were conducted on line. Conversion-electron spectra were taken with a 200 $\mathrm{mm}^{2} \times 3 \mathrm{~mm}$ cooled $\mathrm{Si}(\mathrm{Li})$ detector. All assignments of $\gamma$ ray and internally converted transitions were made on the basis of coincidence information. The ${ }^{184} \mathrm{Au}$ decay scheme is exceedingly complex. In total, we have assigned more than $150 \gamma$ transitions and have established 52 levels in ${ }^{184} \mathrm{Pt}$. 
As mentioned above, a unique feature of the ${ }^{184} \mathrm{Pt}$ level scheme is a second set of coexisting bands, built on the $2^{+}$states of 649 and $1173 \mathrm{keV}$. Confirmation of this identification can be found in the E0 transitions connecting the bands. This is a new aspect to the subject of coexisting shapes in nuclei. In addition to coexisting $\mathrm{K}^{\pi}=0^{+}$ bands, coexisting $\mathrm{K}^{\pi}=2+$ bands can occur at low-excitation energy. We observe these coexisting $\mathrm{K}^{\pi}=2+$ band to be connected to each other by strong $\mathrm{E} 0$ transitions. In particular, we observe E0 transitions between the $\mathrm{I}^{\pi}=2^{+}$members of the two $\mathrm{K}^{\pi}=2^{+}$ bands, but not between these $\mathrm{I}^{\pi}=2^{+}$states and the $2^{+}$states of the $\mathrm{K}^{\pi}=0^{+}$bands; that is, we observe strong E0 components in the $2_{3}^{+} \rightarrow 2_{1}^{+}$and $2_{4}^{+} \rightarrow 2_{2}^{+}$transitions and no E0 components in the $2_{2}^{+} \rightarrow 2_{1}^{+}, 2_{3}^{+} \rightarrow 2_{2}^{+}, 2_{4}^{+} \rightarrow 2_{1}^{+}, 2_{4}^{+} \rightarrow 2_{3}^{+}$transitions. Furthermore, the $I^{\pi}=3^{+}$ members of the two $\mathrm{K}^{\pi}=2^{+}$bands are connected only by an essentially pure E0 transition, that is, no $\gamma$-ray intensity is observed between these states. This also is unprecedented. For more details see DOE/ER/40159-189.

1E.H. Spejewski, R.L. Mlekodaj, and H.K. Carter, Nucl. Inst. Meth. 186, 71 (1981).

\section{On-Line Nuclear Orientation of ${ }^{184} \mathrm{Pt}$}

In a separate experiment, the angular distribution of ${ }^{184} \mathrm{Pt} \gamma$ rays were measured by orienting its parent, ${ }^{184} \mathrm{Au}$, at low temperature. The ${ }^{184} \mathrm{Au}$ nuclei were produced using the same reaction as the spectroscopy experiment described above. The activity was mass separated on line using the UNISOR separator and then transported to the UNISOR Nuclear Orientation Facility ${ }^{1}$. The radioactive nuclei were implanted at $50 \mathrm{kV}$ into a polarized $\mathrm{Fe}$ target in the refrigerator, which operates at a temperature below $7 \mathrm{mK}$ with beam on target. The angular distributions of the $\gamma$ rays were observed with an array of six Ge detectors surrounding the target at a distance of about $10 \mathrm{~cm}$. The anomalously large conversion coefficients of certain transitions in ${ }^{184} \mathrm{Pt}$ are immediately obvious from their large values of the ratio $\alpha_{\mathrm{K}}(\operatorname{expt}) / \alpha_{\mathrm{K}}(\mathrm{M} 1$ theory), which clearly single out those transitions 
connecting the coexisting configurations. To make this argument more quantitative, however, it is necessary to extract the relative E0 admixtures in the transitions. This requires knowledge of the relative amount of $\mathrm{M} 1$ and $\mathrm{E} 2$ radiations present in these $\Delta \mathrm{I}=0$ transitions. The anisotropies of the transitions connecting the levels were analyzed in such a way that the results are independent of any uncertainties resulting from the complex feeding of these levels from higher-lying states. The E2/M1 mixing ratios for many of the transitions were determined from analysis of the angular distributions. Knowledge of the conversion coefficients (corresponding to $\mathrm{E} 0+\mathrm{M} 1+\mathrm{E} 2$ ) and $\mathrm{E} 2 / \mathrm{M} 1$ mixing ratios then permits determination of the relative amounts of $\mathrm{E} 0, \mathrm{M} 1$, and $\mathrm{E} 2$ radiations. We have extracted the \%E0 for 12 of the interband transitions from the data. When combined with lifetime information, these results then allow one to extract $\rho^{2}(\mathrm{E} 0)$ for these cases. For more details, see DOE/ER/40159-189.

${ }^{1}$ I.C. Girit et al., Hyp. Int. 43, 151 (1988).

\section{Lifetimes of the $0_{2}^{+}$Configuration in ${ }^{186} \mathrm{Hg}$ and ${ }^{188} \mathrm{Hg}$.}

Coexisting bands of quite different deformations in $184,186,188 \mathrm{Hg}$ have been known for some time from in-beam reaction 1,2 and radioactive decay 3,4 studies. The latter work also observed electric monpole (E0) transitions in these neutron-deficient $\mathrm{Hg}$ isotopes and precipitated the evolution of this region into a classic example of widely occuring nearly degenerate, nuclear shape coexistence. These data have been extended to include ${ }^{180} \mathrm{Hg}$ (ref. 5), ${ }^{182} \mathrm{Hg}$ (ref. 6), and ${ }^{190} \mathrm{Hg}$ (ref. 7).

A direct measure of the mixing of coexisting shapes in even-even nuclei is the E0 strength between the intruder state and the ground state. ${ }^{8}$ Electric monopole transitions carry direct information on the nuclear wavefunction. Changes in the nuclear radius lead to non-vanishing values for the monopole strength function, $\rho(\mathrm{E} 0)$, provided there is mixing 
between the initial and final nuclear states. ${ }^{8}$ To measure $\rho(E 0)$ experimentally, all that is needed is a measurement of the partial half-life of the $0_{2}^{+}$level.

Half-life limits of $<180$ ps for the $0_{2}^{+}$level in ${ }^{188} \mathrm{Hg}$ and $<200 \mathrm{ps}$ in ${ }^{186} \mathrm{Hg}$ have been reported; 9 and another rough measurement ${ }^{4}$ yielded a half-life of $0.9 \pm 0.3 \mathrm{~ns}$ for the $0_{2}^{+}$ level in ${ }^{184} \mathrm{Hg}$. These $\mathrm{Hg}$ isotopes present a unique challenge to the measurement of $\mathrm{O}_{2}^{+}$ lifetimes in the picosecond range since the complexity of the decay demands a triple coincidence and the major depopulating transitions from the $0_{2}^{+}$(deformed, $B \approx 0.25$ ) levels to the $0_{2}^{+}$(spherical, $B \approx 0.13$ ) is $\mathrm{E} 0$ internal conversion.

A picosecond lifetime measurement system, based on the design 10 at TRISTAN, was developed at UNISOR to measure the lifetimes of the $0_{2}^{+}$configurations in ${ }^{188} \mathrm{Hg}$ and ${ }^{186} \mathrm{Hg}$. The ${ }^{188} \mathrm{Tl}$ and ${ }^{186} \mathrm{Tl}$ parent nuclei were produced as recoils from the reaction of $181 \mathrm{MeV}{ }^{16} \mathrm{O}$ on ${ }^{181} \mathrm{Ta}$. Four detectors employed in various combinations were used in the collection of triple coincidences using a fast-slow timing system. The fast signal was established in one case by a plastic scintillator for $\beta^{+}$particles and $\mathrm{a} \mathrm{BaF}_{2}$ crystal for $\mathrm{x}-$ rays, and in the other case by two $\mathrm{BaF}_{2}$ crystals for $\mathrm{x}$-rays. A Ge $\gamma$-ray detector or a $\mathrm{Si}(\mathrm{Li})$ electron detector were used to select the energy information via the slow timing circuit.

For lifetime measurements in ${ }^{186} \mathrm{Hg}$, fast timing was achieved via the coincidences between $\beta^{+}$particles and the $x$-rays that follow internal conversion. Specific E0 conversion events were selected via the slow timing circuit by gating on the appropriate internal conversion line in the $\mathrm{Si}(\mathrm{Li})$ detector. It is this $\left(\beta^{+}-\mathrm{x}\right)-\mathrm{e}^{-}$triple coincidence that enables one to determine the lifetime of the $0_{2}^{+}$state. A partial ${ }^{186} \mathrm{Tl}$ decay scheme and schematic of the detector system for this measurement along with a sketch of the type of TAC spectrum produced by the system are shown below in the first figure following this section.

The decay of ${ }^{188} \mathrm{Tl}$ populates levels in ${ }^{188} \mathrm{Hg}$ predominately by electron capture. In this case, two $\mathrm{BaF}_{2}$ detectors were used to establish the fast timing. The lifetime for the $\mathrm{O}_{2}^{+}$ level in ${ }^{188} \mathrm{Hg}$ was then measured using the triple coincidence $(\mathrm{x}-\mathrm{x})-\mathrm{e}^{-}$, where one $\mathrm{x}$-ray 
follows electron capture and the other internal conversion. A partial ${ }^{188} \mathrm{Tl}$ decay scheme and schematic of the system for this measurement, as well as the type of TAC spectrum produced by the system, are shown on the final page of this section. This unique system is thoroughly described in DOE/ER/40159-198 and summarized in Section IV A of this report.

The centroids of the time-to-amplitude converter (TAC) signals from triple coincidences of $\left(\beta^{+}-\mathrm{x}\right)-\mathrm{e}^{-}$for the $523-\mathrm{keV}\left(0_{2}^{+} \rightarrow 0_{1}^{+}\right)$and $215-\mathrm{keV}\left(2_{2}^{+} \rightarrow 2_{1}^{+}\right)$transitions in ${ }^{186} \mathrm{Hg}$ were compared to the centroids of the TACs from transitions of known lifetimes. The comparisons, using the centroid shift method, yield a half-life for the $0_{2}^{+}$level of $\leq 52 \mathrm{ps}$ and $48 \pm 27 \mathrm{ps}$ for the $2_{2}^{+}$level. The timing resolution for $\left(\beta^{+}-\mathrm{x}\right)-\mathrm{e}^{-}$coincidences was $1.19 \mathrm{~ns}$, measured as FWHM (full width at half maximum).

The $(\mathrm{x}-\mathrm{x})$ - e- TAC widths for the 413-keV $\left(2_{1}^{+} \rightarrow 0_{1}^{+}\right), 824-\mathrm{keV}\left(0_{2}^{+} \rightarrow 0_{1}^{+}\right)$and the $486-\mathrm{keV}\left(2_{2}^{+} \rightarrow 2_{1}^{+}\right)$transitions in ${ }^{188} \mathrm{Hg}$ were compared, and the lifetime for the $0_{2}^{+}$and $2_{2}^{+}$levels were determined to be $288 \pm 63$ ps and $199 \pm 44$ ps, respectively. The timing resolution achieved for $(\mathrm{x}-\mathrm{x})-\mathrm{e}^{-}$events was $1.58 \mathrm{~ns}$, FWHM.

For ${ }^{188} \mathrm{Hg}$, it is difficult to determine the $\mathrm{O}_{2}^{+} \rightarrow 2_{1}^{+}$branching because this transition energy $(411 \mathrm{keV})$ is nearly identical to that of the intense $2_{1}^{+} \rightarrow 0_{1}^{+}$transition. By using a sum-peak analysis, it was determined that the $411 \mathrm{keV}, 0_{2}^{+} \rightarrow 2_{1}^{+}$, E2 branch is $\leq 42 \%$. In ${ }^{186} \mathrm{Hg}$, the $\mathrm{O}_{2}^{+} \rightarrow 2_{1}^{+}$branch was equally difficult to measure, but determined to be $\leq 28 \%$. Since both of the $0_{2}^{+} \rightarrow 0_{1}^{+}$branches could actually be $100 \%$, the E0 partiai half-lives are expressed as $288_{-63}^{+207} \mathrm{ps}$ in ${ }^{188} \mathrm{Hg}$ and $\leq 72 \mathrm{ps}$ in ${ }^{186} \mathrm{Hg}$. Hence, the $\rho^{2}(\mathrm{E} 0)$ values for ${ }^{188} \mathrm{Hg}$ and ${ }^{186} \mathrm{Hg}$ were calculated, using the method of Kantele, 13 to be $5.5_{-2.3}^{+1.5}$ and $\geq 32$, respectively.

Large E0 strength is an indication of strong mixing between nuclear states with quite different mean-square radii. The results determined here for $\rho^{2}(E 0)$ in ${ }^{188} \mathrm{Hg}$ and ${ }^{186} \mathrm{Hg}$ are consistent ${ }^{8,12}$ with the coexistence of shapes built upon a proton 2-hole configuration (near spherical) and a proton 2-particle, 4-hole configuration (deformed). Based on these 
$\rho^{2}$ (E0) values, the mixing matrix element $V_{0}$, calculated using the formalism of Kantele, ${ }^{13}$ are $73_{-18}^{+9} \mathrm{keV}$ for the $\mathrm{O}_{2}^{+}$level in ${ }^{188} \mathrm{Hg}$ and $>111 \mathrm{keV}$ for the $0_{2}^{+}$level in ${ }^{186} \mathrm{Hg}$. These results suggest that the early measurement of the half-life of the $0_{2}^{+}$state in ${ }^{184} \mathrm{Hg}^{4}, 0.9 \pm$ $0.3 \mathrm{~ns}$ should be remeasured and that stricter limits on the $0_{2}^{+} \rightarrow 2_{1}^{+}$branching in all these $\mathrm{Hg}$ isotopes should be determined.

\begin{tabular}{lllllllll}
\hline Nucleus & $\begin{array}{l}\mathrm{E}\left(0_{2}^{+}\right) \\
\mathrm{keV}\end{array}$ & $\mathrm{T}_{1 / 2}\left(0_{2}^{+}\right)$ & $\mathrm{E} 0$ & $\mathrm{~T}_{1 / 2}(\mathrm{E} 0)$ & $\rho^{2}(\mathrm{E} 0) \times 10^{3}$ & $\mathrm{~V}_{0}$ & $\mathrm{E}\left(2_{2}^{+}\right)$ & $\mathrm{T}_{1 / 2}\left(2_{2}^{+}\right)$ \\
& branch & $\mathrm{ps}$ & & $\mathrm{keV}$ & $\mathrm{keV}$ & $\mathrm{ps}$ \\
\hline $188 \mathrm{Hg}$ & 824 & $288 \pm 63$ & $\geq 58 \%$ & $288_{-63}^{+207}$ & $5.5_{-2.3}^{+1.5}$ & $73_{-18}^{+9}$ & 881 & $199 \pm 44$ \\
$186 \mathrm{Hg}$ & 523 & $\leq 52$ & $\geq 72 \%$ & $\leq 72$ & $\geq 32$ & $\geq 111$ & 620 & $48 \pm 27$ \\
\hline
\end{tabular}

${ }^{1}$ N. Rud, D. Ward, H. R. Andrews, R. L. Graham and J. S. Geiger, Phys. Rev. Lett. 31, 1421 (1973).

2D. Protel, R. M. Diamond and F. S. Stephens, Phys. Rev. Lett. B 48, 102 (1974).

3J. H. Hamilton, et al., Phys. Rev. Lett. 35, 562 (1975).

4J. D. Cole et al., Phys. Rev. Lett. 35, 1185 (1976).

$5_{G}$. D. Dracoulis et al, Phys. Lett. B 208, 365 (1988).

${ }^{6}$ W. C. Ma et al., Phys. Lett. B 139, 276 (1984).

${ }^{7}$ M. O. Kortelahti et al, Phys. Rev. C 43, 484 (1991).

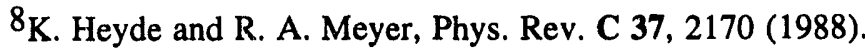

${ }^{9}$ V. Berg, Future Directions in Studies of Nuclei Far from Stability (North Holland) 361 (1980).

${ }^{10}$ H. Mach, R. L. Gill, and M. Moszynski, Nucl. Inst. Meth. A 280, 49 (1989).

11 J. Kantele, Nucl. Inst. Meth. A271, 625 (1988).

${ }^{12}$ K. Heyde, C. De Coster, J. Ryckevusch, and M. Waroquier, Phys. Lett. B 218, 287 (1989).

13J. Kantele, Heavy Ions and Nuclear Structure, Harwood Academic Pub., 1984, p. 391. 

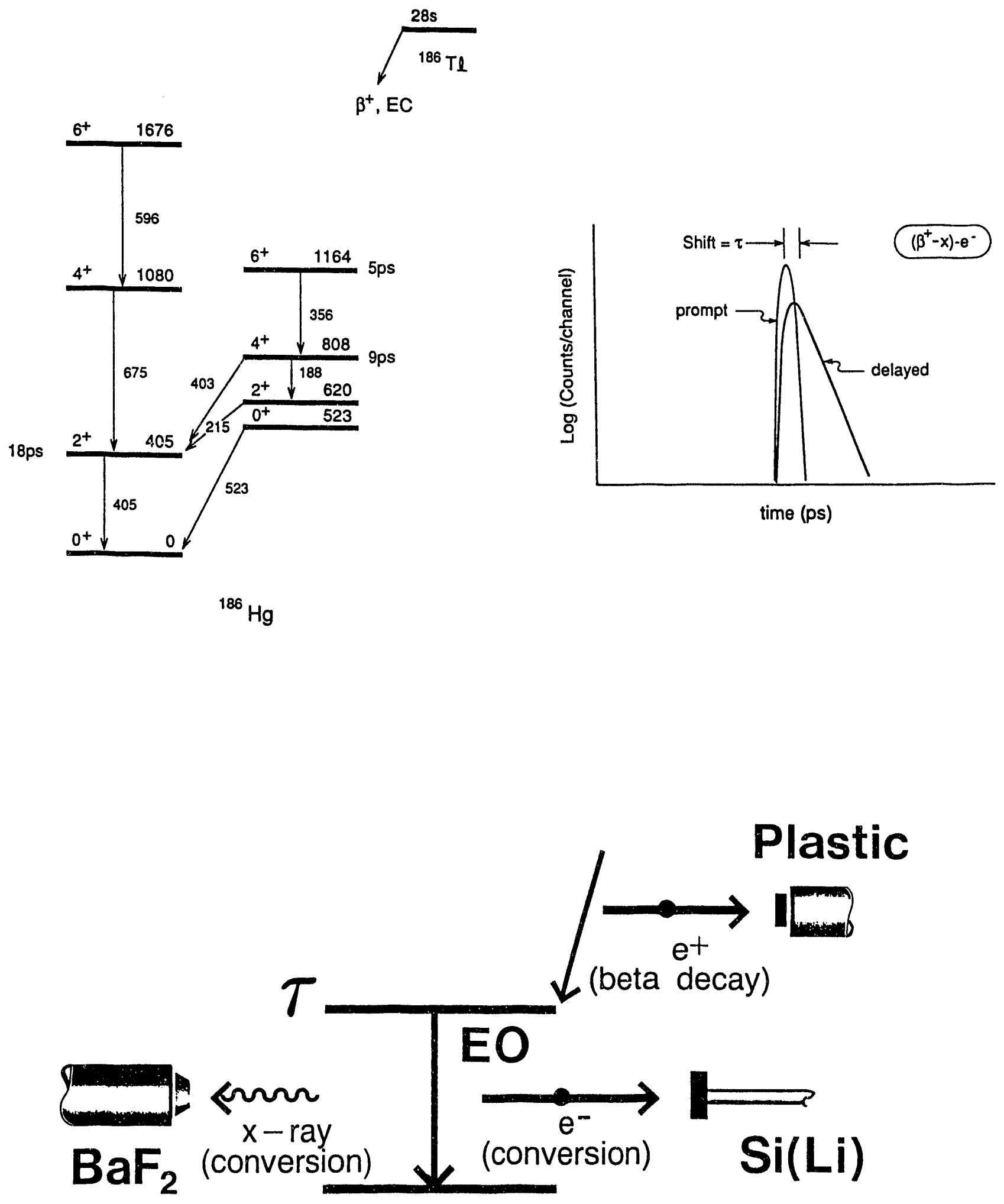

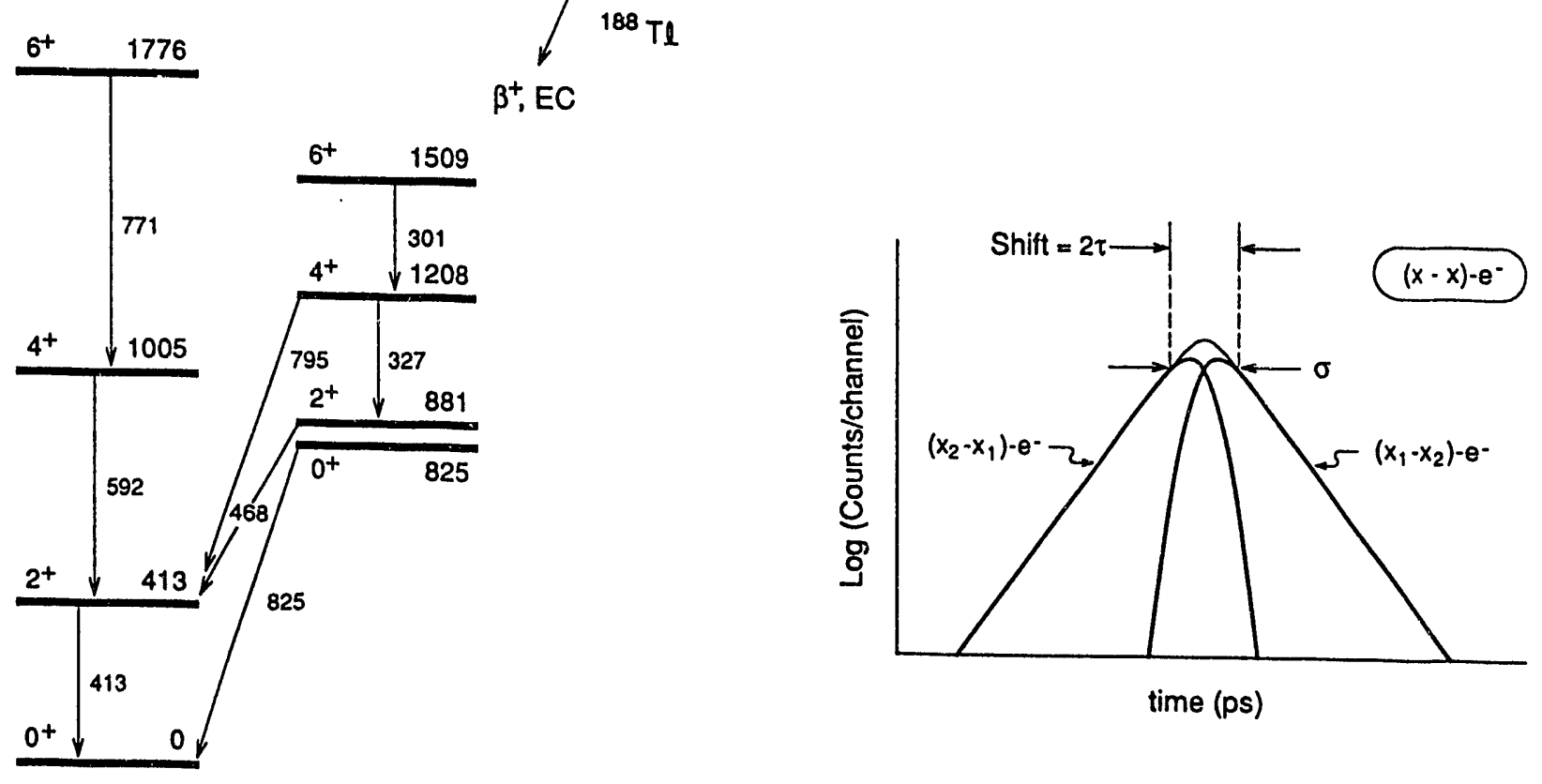

${ }^{188} \mathrm{Hg}$

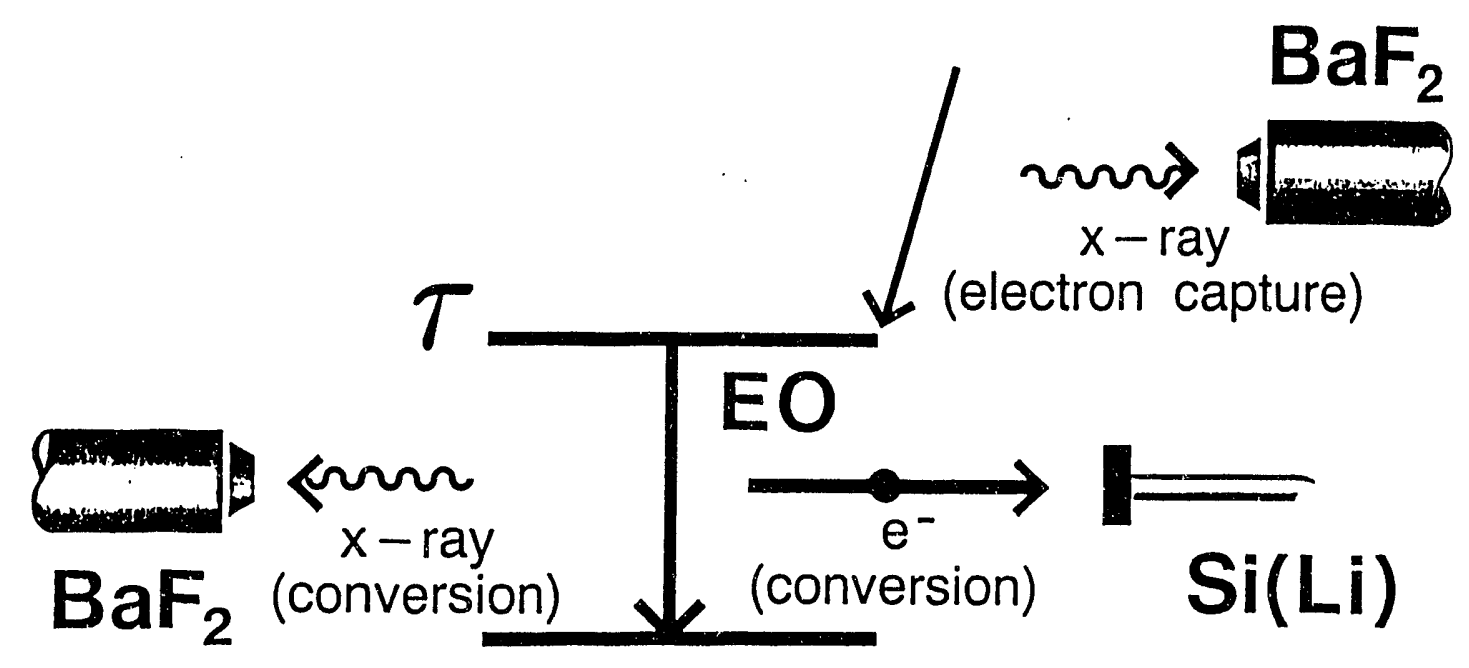




\section{Shape Coexistence and Complete Spectroscopy in ${ }^{187} \mathrm{Au}$ from the $187 \mathrm{~m} \mathrm{Hg}$ and $187 \mathrm{gHg}$ Decays.}

In our work on shape coexistence in the odd-mass Au nuclei, we have attempted to establish the detailed quantitative features of the energies of the intruder states and to determine the mixing between the coexisting states. Many answers are already available. For example, in most cases an overall parabolic energy dependence is observed with a minimum near mid-shell for the neutrons $(\mathrm{N}=104)$. However, significant portions of all these parabolas are missing, most notably when the members of the intruder state bands lie above $\approx 1 \mathrm{MeV}$. This is because the detailed spectroscopy necessary to extract the relevant information increases with difficulty with increasing excitation energy. We have determined that the $h_{9 / 2}$ proton intruder has penetrated the $\mathrm{Z}=82$ closed shell to become an excited state at $325 \mathrm{keV}$ in ${ }^{189} \mathrm{Au}, 121 \mathrm{keV}$ in ${ }^{187} \mathrm{Au}$, and to become the ground state in ${ }^{185} \mathrm{Au}$.

In the core-particle coupling picture, the (A-1) core for odd-mass $\mathrm{Au}$ isotopes is $\mathrm{Pt}$, while the $(\mathrm{A}+1)$ core is $\mathrm{Hg}$. The shape coexisting possibilities with $\mathrm{Pt}$ involve the $\pi(4 \mathrm{~h})$ spherical ${ }^{2}$ and $\pi(2 p-6 h)$ deformed configurations, and for $\mathrm{Hg}$ the $\pi(2 \mathrm{~h})$ spherical $^{2}$ and $\pi(2 \mathrm{p}-4 \mathrm{~h})$ deformed configurations. ${ }^{1}$ Various couplings of these configurations with the odd-proton particle or hole in the Au isotope are possible. For example, proton holes in the $\mathrm{Au}$ isotopes can couple to both the spherical and deformed configurations in the corresponding $\mathrm{Hg}$ cores, while proton particles in the $\mathrm{Au}$ isotopes can couple to the two types of structure in the Pt cores. We have observed 3 all four of these possibilities in both ${ }^{185} \mathrm{Au}$ and ${ }^{187} \mathrm{Au}$. One of the identifiers of these configurations has been the observation of transitions with large E0 components for the I $\rightarrow \mathrm{I}$ transitions between the shape coexisting configurations, as described above for ${ }^{184,185} \mathrm{Pt}$.

The ${ }^{187} \mathrm{Au}$ nucleus, being transitional (i.e. the $\mathrm{h}_{9 / 2}$ intruder is not yet the ground state), has the richest structure in terms of mixed configurations. Thus, it was decided to push the spectroscopy on this decay to an unheard of sensitivity and completeness in order to enable 
us to systematically track the states in ${ }^{185} \mathrm{Au}$, where the $\pi \mathrm{h} 9 / 2^{+1} \otimes \pi(2 \mathrm{p}-6 \mathrm{~h})$ couffiguration is the ground state, to those in ${ }^{189} \mathrm{Au}$, where that configuration is at considerably higher energy.

The extensive analysis of the massive data sets on the ${ }^{187} \mathrm{Tl} \rightarrow{ }^{187 \mathrm{gHg}} \rightarrow{ }^{187} \mathrm{Au}$ and ${ }^{187} \mathrm{~m} \mathrm{Hg} \rightarrow{ }^{187} \mathrm{Au}$ decays is complete and manuscripts will soon be finished. The data were taken at UNISOR using the ${ }^{176} \mathrm{Hf}\left({ }^{19} \mathrm{~F}, 8 \mathrm{n}\right){ }^{187} \mathrm{Tl}(\beta / \mathrm{EC}){ }^{187} \mathrm{Hg}$ and ${ }^{176} \mathrm{Hf}\left({ }^{16} \mathrm{O}, 5 \mathrm{n}\right){ }^{187} \mathrm{Hg}$ reactions. The $\beta$ decay of ${ }^{187} \mathrm{Tl}$ predominantly populates the $3 / 2^{-}$ ground state of ${ }^{187} \mathrm{Hg}$ (2.4 minutes) and, consequently, the low-spin states of ${ }^{187} \mathrm{Au}$. The direct production of ${ }^{187} \mathrm{Hg}$ will preferentially populate the $13 / 2^{+}$isomer in ${ }^{187} \mathrm{Hg}(1.7$ minutes) and, consequently, more high-spin states in ${ }^{187} \mathrm{Au}$. The decay of directly produced ${ }^{187} \mathrm{Hg}$ was analyzed first. About 430 transitions and 145 levels have been extracted from the data and assigned to the levels in ${ }^{187} \mathrm{Au}$. The analysis of $187 \mathrm{~m}, \mathrm{gTl}$ decay brought these numbers up to 490 and 180 , respectively, mostly through identification of transitions and levels related to the decay of $187 \mathrm{gHg}$ (low spin) which are not populated in the decay of $187 \mathrm{~m} \mathrm{Hg}$ (high spin). The higher complexity of the second analysis is due to the additional contamination from two sources: the ${ }^{187} \mathrm{Tl} \rightarrow{ }^{187} \mathrm{Hg}$ decay and the internal decay of the $9 / 2^{-187 \mathrm{~m} T l}$ isomer. The relation between life times of ${ }^{187} \mathrm{Tl},{ }^{187} \mathrm{Hg},{ }^{187} \mathrm{Au}$, and ${ }^{187} \mathrm{Pt}$ nuclei, as well as their parallel direct production during the experiments, resulted in the intensity of the strongest transition in ${ }^{187} \mathrm{Pt}, 1332 \mathrm{keV}$, being 34 units in the ${ }^{187} \mathrm{Hg}$ decay and 65 units in the ${ }^{187} \mathrm{Tl}$ decay; and the strongest transition in ${ }^{187} \mathrm{Hg}, 349 \mathrm{keV}$, being 45 units in the ${ }^{187} \mathrm{Tl}$ decay, relative to 100 units of intensity for the $233 \mathrm{keV}$ transition in ${ }^{187} \mathrm{Au}$.

A group of states have been located which correspond to several series of the particlecore couplings $\left({ }^{186} \mathrm{Pt}[\pi(2 \mathrm{p}-6 \mathrm{~h})] \otimes \mathrm{h}_{9 / 2}^{+1},{ }^{186 \mathrm{Pt}}[\pi(4 \mathrm{~h})] \otimes \mathrm{h}_{9 / 2}^{+1},{ }^{188} \mathrm{Hg}[\pi(2 \mathrm{p}-4 \mathrm{~h})] \otimes \mathrm{h}_{11 / 2}^{-1}\right.$, and $\left.{ }^{188} \mathrm{Hg}[\pi(2 \mathrm{~h})] \otimes \mathrm{h}_{11 / 2}^{-1}\right)$, as well as levels near $2 \mathrm{MeV}$ that correspond to a coupling between a proton and the states in the core with energy greater than the pairing gap. We have also identified a number of transitions, seen in the lower-spin part of the high-spin data, ${ }^{4}$ which 
lie in the domain of spins of the decay data, 5 such as the $478 \mathrm{keV}, 417 \mathrm{keV}, 544 \mathrm{keV}$, and $455 \mathrm{keV}$ transitions. The analysis of these data has been the most complete of any odd-A nucleus that we have attempted. We have, on a routine basis, placed transitions with intensities as low as 0.2 relative to 100 for the $233.4 \mathrm{keV}$ transition. An extensive analysis of multiplets has yielded 52 transitions with differences in energy that are between $0.5 \mathrm{keV}$ and $1 \mathrm{keV}$ (instrumental resolution, FWHM, being $\approx 2 \mathrm{keV}$ ), and 81 transitions with separations $\leq 0.5 \mathrm{keV}$. A total of over 2000 spectra (coincidence gates) were carefully analyzed to establish coincidence relations. More than $200 \gamma$-gated gammas and over $50 \gamma$ gated electrons were analyzed to extract the separate intensities of the transitions in coincidence with the gated ones. This process enabled us to separate the intensities of the multiplets that were not separable in the ungated spectra. The analysis of the conversion electron spectra, using spectra of $\gamma$-gated electrons and $\gamma$-gated gammas, yielded $\approx 280$ conversion coefficients. Multipolarities, as well as both sets of intensities (from the decay

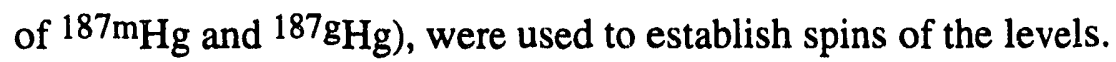

An iteration procedure, using both sets of $\gamma$-ray intensities (i.e. from ${ }^{187} \mathrm{Tl}$ and from ${ }^{187} \mathrm{Hg}$ ) was used to separate the intensilies corresponding to the decays of the ${ }^{187} \mathrm{Hg} 3 / 2$ ground state and the ${ }^{187} \mathrm{Hg} 13 / 2+$ isomeric state. The procedure requires the determination of two constants: one is a ratio between ${ }^{187} \mathrm{Tl}$ and ${ }^{187} \mathrm{Hg}$ decay intensities for pure lowspin transitions in ${ }^{187} \mathrm{Au}$ (transitions between pure low-spin levels, fed only by the $3 / 2$ decay). The other is a ratio between ${ }^{187} \mathrm{Hg}$ decay and ${ }^{187} \mathrm{Tl}$ decay intensities for pure highspin transitions in ${ }^{187} \mathrm{Au}$ (transitions between pure high-spin levels, fed only by the $13 / 2^{+}$ decay). When the appropriate constants were extracted and used in the iterative procedure, the results converged and revealed that the decay paths are quite different: The $203.4 \mathrm{keV}$ transition is the strongest in the ${ }^{187} \mathrm{Hg} 3 / 2$ - decay, while the $233.4 \mathrm{keV}$ is the strongest in the ${ }^{187} \mathrm{Hg} 13 / 2^{+}$decay. The decay of the ${ }^{187} \mathrm{Hg} 3 / 2^{-}$reveals 61 mostly low-spin levels in ${ }^{187} \mathrm{Au}$ connected by 146 transitions. Of these, 37 levels are pure (low-spin decay). The 
decay of the ${ }^{187} \mathrm{Hg} 13 / 2^{+}$reveals 144 mostly high-spin levels in ${ }^{187} \mathrm{Au}$ cunnected by 348 transitions. Of these, 119 levels are pure (high-spin decay).

In these data we located seven transitions with $\mathrm{E} 0+\mathrm{M} 1+\mathrm{E} 2$ multipolarity, that is, transitions for which $\alpha_{K}($ Expt $)>\alpha_{K}$ (M1 theory). The E0+M1+E2 interband transitions between shape coexisting configurations where $\alpha_{K}$ (Expt) $\leq \alpha_{K}$ (M1 theory) are not identifiable through IC measurements, but can be connected to the configurations through other means (e.g. B(E2) values). The four coexisting structures discussed above are clearly identified.

\footnotetext{
${ }^{1}$ E.F. Zganjar, and J.L. Wood, Hyp. Int. 43, 321 (1988).

${ }^{2}$ Here spherical means more spherical.

${ }^{3}$ C.D. Papanicolopulos, M.A. Grimm, J.L. Wood, E.F. Zganjar, M.O. Kortelahti, J.D. Cole, and H.K. Carter, Z. Phys. A330, 371 (1988)

${ }^{4}$ C. Bourgeois, M.G. Poquet, N. Perrin, H. Segolle, F. Hannachi, G. Bastin, and F. Beck, Z. Phys. A333, 5 (1989).

${ }^{5}$ D. Rupnik, E.F. Zganjar, and J.L. Wood, 1991, ORNL-6689 Physics Division, Progress Report 91, p 120.
}

\section{Other Studies}

Structure of ${ }^{187} \mathrm{Ir}$ from the decay of oriented ${ }^{187} \mathrm{Pt}$

The nuclear structure of odd-proton ${ }^{187}$ Ir was studied following the radioactive decay of mass-separated ${ }^{187} \mathrm{Pt}$. Two experiments were done: a spectroscopy study in which $\gamma$ ray and electron singles and $\gamma-\gamma$ angular correlations were observed, and a nuclear orientation study in which $\gamma$-ray angular distributions were measured from ${ }^{187} \mathrm{Pt}$ oriented at low temperature.

Based on these results, a new decay scheme has been constructed including approximately $92 \%$ of the decay intensity with levels up to about $2.4 \mathrm{MeV}$. A new multiplet of levels has been confirmed in the $2.4 \mathrm{MeV}$ region; no previous structure in this nucleus had been known above $1.5 \mathrm{MeV}$. A significant share of the decay inter.sity 
proceeds through these levels and analysis of the decay scheme of the low-lying states is not possible without knowledge of the feedings through this high-energy multiplet.

From the nuclear-orientation and internal-conversion data, we have obtained E2/M1 multipole mixing ratios for many of the low-lying transitions. Mixing ratios calculated using a particle-plus-triaxial-rotor model show excellent agreement with experimental values in both inagnitude and phase.

A preliminary report ${ }^{1}$ on this work is available. A similar study of the decay of ${ }^{188} \mathrm{Pt}$ has been done. Data from that work are being analyzed.

\footnotetext{
${ }_{1}^{1}$ M.A. Gummin, K.S. Kranc, Y. Xu, T. Lam, E.F. Zganjar, J.B. Breitenbach, B.E. Zimmerman, P.F. Mantica, and H.K. Carter, Second International Conference on On-Line Nuclear Orientation and Related Topic:s, Opk Ridge, Tennessee, October 16-19, 1991.
}

$\underline{\text { Structure of }{ }^{199} \mathrm{~Pb} \text { from }{ }^{199} \mathrm{Bi} \text { C ecay }}$

Shape coexistence in odd $\mathrm{A}$ nuclei in the $\mathrm{Pb}$ region has been extensively studied from both an experimental and theoretical viewpoint. ${ }^{1}$ Because the protons occupy levels near the $Z=82$ closed shell and the neutrons occupy levels near the middle of the $N=126$ shell, there is the possibility that nearly spherical and deformed states arising from the excitation of protons across the $\mathrm{N}=82$ shell can coexist at low energy in this region. In odd $-\mathrm{A} \mathrm{Pb}$ isotopes, the $13 / 2^{+}$deformed excited states arising from the coupling of the $i_{13 / 2}$ state to the deformed intruder bandhead have been found 2,3 in ${ }^{195,197} \mathrm{~Pb}$. The goal of the present work was to obtain a more complete decay scheme for ${ }^{199} \mathrm{~Pb}$, and to contribute to the systematic study of odd- $\mathrm{A} \mathrm{Pb}$ isotopes in this region.

The decay of ${ }^{199} \mathrm{Bi}$ was studied utilizing the UNISOR Isotope Separator on-line to the Holifield Heavy-Ion Research Fácility tandem accelerator. Ions of ${ }^{199} \mathrm{Bi}$ were produced by bombarding a $53 \mathrm{mg} / \mathrm{cm}^{2}$ stack of Re foils with a $155-\mathrm{MeV} 16 \mathrm{O}$ beam and collected on a moving tape collector, which moved the activity to a measurement station around which were placed three $\mathrm{Ge} \gamma$-ray detector; and a $\mathrm{Si}(\mathrm{Li})$ electron detector. Multiscaled conversion electron and $\gamma$-ray singles data, as well as $\gamma-\gamma$ and $\gamma$-e coincidences, were collected. 
From the data, a total of 286 transitions were attributed to the decay of ${ }^{199} \mathrm{Bi}$, of which 149 transitions were placed in the level scheme. A total of 120 new transitions and 33 new levels were added to the previous scheme. Since the ground-state spins of ${ }^{199} \mathrm{~Pb}$ and ${ }^{199} \mathrm{Bi}$ are $3 / 2^{-}$and $9 / 2^{-}$, respectively, the bulk of the decay proceeds to the first excited 5/2- state. Previous studies revealed no ground-state transitions, proposing instead an upper limit of $9.3 \mathrm{keV}$ for the first excited state. We have deduced, via the $1022.8 \mathrm{keV}, 1034.0 \mathrm{keV}$, $1146.4 \mathrm{keV}$, and $1157.5 \mathrm{keV}$ gates, that each of these decay from the same state to both the ground and first excited states. This establishes that the energy of the first excited state is $11.2 \mathrm{keV}$.

The electron singles and coincidence data allowed for the determination of 86 (47 new) conversion coefficients and the observation of several E0 transitions, which have been interpreted to be the signature of shape coexisting states. We have observed a $1268.1 \mathrm{keV}$ transition that decays to the $436.5 \mathrm{keV} 13 / 2^{+}$state, which is the first positive-parity excited state. The observed $\alpha_{\mathrm{K}}$ value is 1.3 times larger than that expected for an M1 transition. Thus, the state at $1704.6 \mathrm{keV}$ is proposed to be the deformed bandhead. Other E0 transitions suggest possible deformed states at 1573.9, 1754.4, and $1937.2 \mathrm{keV}$.

\footnotetext{
1J.L. Wood, K. Heyde, W. Nazarewicz, M. Huyse, and P. Van Duppen, Phys. Rept. 215, 101 (1992).

2J.C. Griffin et al., Nucl. Phys. A531, 401 (1991).

3J. Vanhorenbeeck et al., Nucl. Phys. A531, 63 (1991).
}

\section{B. Superdeformation}

Superdeformation (nuclear axis ratios of 2:1) was first proposed to explain ${ }^{1}$ fission isomers observed ${ }^{2}$ in some actinide nuclei. It was realized much later that superdeformed shapes could occur at high angular momentum in lighter nuclei. This was first discovered by $\mathrm{Twin}^{3}$ who observed a superdeformed band of 19 discrete lines in 152Dy. This set off a great deal of interest in the mechanisms responsible for these exotic shapes and 
superdeformation has now been observed in many regions of the nuclear chart. The impressive properties of superdeformation that have come from all these experiments is the essentially constant energy spacing between transitions (picket fence), the unexpectedly strong population of these bands at high spins, the occurrence of superdeformed bands with identical transition energies in nuclei differing by one or two mass units, and the apparent lack of a link between the superdeformed states and yrast levels. It is this latter property that is the focus of the work discussed below.

Since this work describes searches for population of superdeformed states using $\beta$ decay, it is important to note that due to the dissimilar parent ground state and daughter superdeformed state, $\beta$-decay population of the superdeformed states would be expected to be highly hindered. Nevertheless, recent studies ${ }^{4}$ of the $\beta^{+}$decay of 232,234 An to $232,234 \mathrm{Pu}$ have revealed a weak delayed-fission branch $\left(\sim 6 \times 10^{-5}\right.$ for ${ }^{234} \mathrm{Am}$ and $\sim 7 \times 1 \mathrm{p}^{-4}$ for ${ }^{232} \mathrm{Am}$ ), indicating that the fission isomer in ${ }^{232,234} \mathrm{Pu}$ might be populated in decay. Because the calculated excitation energies of the second minimum in the $\mathrm{Hg}-\mathrm{Tl} \mathrm{Pb}$ reglon are $\sim 3-7 \mathrm{MeV}, \mathrm{Q}_{\beta}$ must be rather large for population of the superdeformed band even to be energetically possible through $\beta^{+}$decay. Additionally, allowed $\beta$-decay transitions $(\Delta \mathrm{I}$ $= \pm 1, \Delta \pi=$ yes $)$ and first-forbidden unique $\beta$-decay transitions $(\Delta \mathrm{I}= \pm 2, \Delta \pi=$ yes $)$ restrict the spin of the decaying state to spins near that of the known SD states.

\footnotetext{
1V.M. Strutinsky, Nucl. Phys. A122, 1 (1968).

2S.M. Polikanov et al., Sov. Phys. JETP 15, 1016 (1962).

${ }^{3}$ P.J. Twin et al., Phys. Rev. Lett. 57, 811 (1985).

${ }^{4}$ H.L. Hall et al., Phys. Rev. C42, 1480 (1990); and Phys. Rev. C41, 618 (1990).
} 


\section{Search for Population of Superdeformed States in ${ }^{192} \mathrm{Hg}$ Using ${ }^{192} \mathrm{Tl}$ $\beta+$ Decay}

An impressive number of new results in the $A=190$ region have become available recently, but it is ${ }^{192} \mathrm{Hg}$ which is regarded as the analogue of ${ }^{152} \mathrm{Dy}$ for the $\mathrm{A}=190$ region since in that region shell gaps are calculated to occur ${ }^{1}$ at large deformation for both $Z=80$ and $\mathrm{N}=112$. Superdeformed states were first discovered ${ }^{2,3}$ in ${ }^{192} \mathrm{Hg}$ through in-beam reaction spectroscopy, with the bands identified (indirectly) down to about $8^{+}$. The band heads and lower members of these bands have not been observed, nor have the connection between the superdeformed structures and the ground state been found. In fact, this inability of in-beam reaction spectroscopy to locate the superdeformed structures (energy wise) is a common problem, and only in ${ }^{135} \mathrm{Nd}$ has the superdeformed band been connected ${ }^{4}$ to states for which the decay path is known.

While most of the superdeformed band transitions have been found to be in coincidence with transitions between low-spin yrast states in the same nucleus, none of the linking transitions have been located. Several explanations have been put forth to account for this. One proposes that the decay-out process is statistical in nature and that many decay paths share the intensity. 5 Another suggests that E0 transitiuns could play an important role. ${ }^{6}$ The latter was tested ${ }^{7}$ for ${ }^{192} \mathrm{Hg}$ by in-beam spectroscopy by looking at the K-shell $\mathrm{x}$-ray yield in coincidence with superdeformed transitions. The rationale underlying this approach is that strong E0 transitions would be accompanied by intense ionization in the $\mathrm{K}$-shell. The direct measurement of E0 decay in-beam is rather difficult, thus, this indirect technique, although not as definitive as direct spectroscopy, is more suitable to in-beam work. The results ${ }^{7}$ for ${ }^{192} \mathrm{Hg}$ tend to suggest that E0 internal conversion decay is not the mechanism by which the superdeformed band decay to other states.

More recently, however, a proposal ${ }^{8}$ was put forth that in heavy superdeformed nuclei at low spins, M1 transitions, enhanced by internal conversion, may compete favorably 
with E2 $\gamma$ rays. For strongly coupled bands with large $B(M 1)$ values, the decay could proceed between two signature partner bands with very few $\gamma$ rays emitted. Experimental evidence for the $\mathrm{M} 1$ cross talk dominated by internal conversion has been seen ${ }^{8}$ in superdeformed bands in ${ }^{193} \mathrm{Hg}$.

\section{Search Based on Electron-Electron Coincidences}

We constructed a spectrometer containing two $\mathrm{Si}(\mathrm{Li})$ detectors, one designed for very low-energy electrons and one for medium- to high-energy electrons, set so that each could view the radioactivity unimpeded by any material (such as the tape upon which the activity is deposited and carried to the detector station). The idea behind this experiment is that since the transition energy between low-spin levels in the superdeformed bands become quite low, e.g. $\approx 32 \mathrm{keV}$ for the $2^{+} \rightarrow 0^{+}$(extrapolating from the known $3214 \mathrm{keV} 10^{+} \rightarrow 8^{+}$ transition), they will be almost entirely converted. Thus, coincidence correlations between very low-energy electrons and medium-energy electrons, or high-energy ones if they are E0, might pick out one of the transitions observed in-beam. It was considered critical to allow for the possibility of a high-energy E0 transition in these measurements since coexisting bands in this region are, without exception, observed to be connected by intense $\mathrm{E} 0$ transitions. 9

We performed a 12-shift experiment using this technique, to search for superdeformed states in ${ }^{192} \mathrm{Hg}$ with $\mathrm{I} \leq 8$ by studying the excited states of ${ }^{192} \mathrm{Hg}$ populated in the $\beta^{+}$ decay of $192 \mathrm{~m}, \mathrm{gTl}\left(10.8 \mathrm{~m}, 7^{+}\right.$and $9.4 \mathrm{~m}, 2^{-}$respectively) at the UNISOR facility. The $\beta^{+}$decay of the $\mathrm{J}^{\pi}=7^{+}$isomer in ${ }^{192} \mathrm{Tl}$ is known ${ }^{10}$ to populate states in ${ }^{192} \mathrm{Hg}$ with $\mathrm{J} \leq 9$. Since QEC is $6.4 \pm 0.2 \mathrm{MeV}$ for the ${ }^{192 \mathrm{gTl}} \rightarrow{ }^{192} \mathrm{Hg}$ decay, and since the superdeformed bandhead was expected ${ }^{1}$ to lie in the $3.5-\mathrm{MeV}$ range, there are no energy or angular momentum restrictions on the population of this superdeformed structure via $\beta^{+}$decay. Other unknown hindrances are, of course, operative. [Note, since the experiments on 
${ }^{192} \mathrm{Hg}$ were done, a recent paper indicates considerably higher excitation energy for the superdeformed configuration. 11

A total of $2.2 \times 10^{7}$ e-e, $3.9 \times 10^{7}$ e- $\gamma$ and $1.1 \times 10^{8} \gamma-\gamma$ events were obtained. No events involving $\alpha$-particles were observed. Preliminary analysis of the data reveal that if the superdeformed structure is populated in the $192 \mathrm{~m}, \mathrm{gTl}$ decay, the population intensity is less than $1 \%$. We have shown ${ }^{9}$ in ${ }^{190} \mathrm{Hg}$ that coexisting bands with populations < $1 \%$ can indeed be located (energy) and quantified (spin, parity) with meticulous analysis of the data. Since nothing was observed at the $1 \%$ level, a new analysis approach to push these limits to the $0.1 \%$ level are currently being developed. It will be implemented in the coming months.

\section{Search Based on Internal Pair Formation Spectroscopy}

In an attempt to improve the sensitivity of the search, and to simultaneously determine if high energy E0 transitions are involved in the decay path between the superdeformed states and the yrast states, we reconfigured our existing conversion electron spectrometers to do internal pair formation (IPF) spectroscopy as shown in the first figure following this section. We referred to this configuration as our prototype IPF spectrometer. Since we have shown $n^{9}$ that the $I \rightarrow I$ transitions connecting shape coexisting configurations have large EO components, the possibility exists that E0 transitions of high energy may be involved. At energies below a few $\mathrm{MeV}$, for $\mathrm{Z}=80$, internal conversion is essentially the only mechanism by which an E0 transition can proceed. At higher energies, however, internal pair formation provides another mechanism for the E0 decay -- and one which does not produce a K-shell x-ray. Thus, if IPF were to dominate the process, neither the previous measurement, which searched for correlated K-shell electrons, nor the in-beam study, ${ }^{7}$ which searched for correlated K-shell x-rays, would have observed any E0 decay.

A $150 \mathrm{MeV} 16 \mathrm{O}$ beam on natural tungsten was used to produce the ${ }^{192} \mathrm{Tl}$ activity. The reaction products were separated on-line at the UNISOR isotope separator and transported by metalized mylar tape to a counting station where the prototype IPF spectrometer was 
located. The electron detectors viewed the activity (on the mylar tape) horizontally with 180 degree geometry, while two Ge $\gamma$-ray detectors viewed the activity vertically, also with 180 degree geometry. In addition, an x-ray detector was positioned orthogonal to both of these axes. Six time-to-amplitude converters were used in order to record all possible combinations of coincident events and to later enable the specification of threefold events. This is necessary since the specification of a discrete high-energy E0 transition is made by adding the energies of the coincident electron and positron which result from the IPF process. This is a two-fold event. In order to have a coincidence between this electron-positron summed event with an $\mathrm{x}$-ray, $\gamma$ ray, or annihilation photon, three-fold events are necessary. It is this triple coincidence that gives this method its improved sensitivity.

The second figure following this narrative shonw's the matrix obtained from electronpositron coincidences. If a positron is detected by $、$ : cletector $\left(E_{1}\right)$ then the correlated electron appears in the second $\left(\mathrm{E}_{2}\right)$. The reverse is siso irue since the $\mathrm{Si}(\mathrm{Li})$ detectors by themselves cannot distinguish positrons and electrons. The third figure shows the result of sweeping a window across the $\mathrm{e}^{-}-\mathrm{e}^{+}$matrix as indicated by the black rectangular slice sketched on the figure of the $\mathrm{e}^{-}-\mathrm{e}^{+}$matrix. The position of the rectangular slice in the $E_{1} / E_{2}$ plane represents the sum of the energy of the correlated particles. For an E0 transition, proceeding by the IPF process, $\mathrm{E}_{\mathrm{e}+}+\mathrm{E}_{\mathrm{e}_{-}}+1022 \mathrm{keV}$ is $\mathrm{E} 0$ transition energy. The number of events in this window is plotted as a function of the $E_{1}+E_{2}$ energy in the third figure. This represents two-fold events. The structure at $1600-1750 \mathrm{keV}$ may be of significance, but that will only be determinable following the analysis of the data with three-fold restrictions. That analysis is currently underway. [Again, it is noted that a recent paper ${ }^{11}$ indicates that the superdeformed excitation energy is at a higher energy than first predicted by theory, thus further limiting the probability of superdeformed state population in the ${ }^{192} \mathrm{Tl}$ decay]. 
${ }^{1}$ R.R. Chasman, Phys. Lett. B219, 227 (1989).

2P. Bonche et al., Nucl. Phys. A500, 308 (1989).

${ }^{3}$ D. Ye et al., Phys. Rev. C41, R131 (1990).

${ }^{4}$ E.M. Beck et al., Phys. Rev. Lett. 58, 2182 (1987).

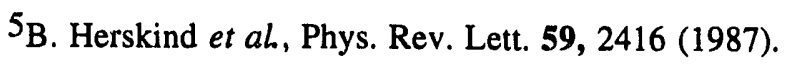

6E.F. Zganjar and J.L. Wood, Nucl. Phys. A520, 427C (1990).

${ }^{7}$ E.F. Moore et al, Phys. Lett. B258, 284 (1991).

${ }^{8}$ P.B. Semmes, I. Ragnarsson and S. Åberg, Phys. Rev. Lett. 68, 460 (1992).

${ }^{9}$ M.O. Kortelahti et al., Phys. Rev. C43, 484 (1991).

${ }^{10}$ D.C. Sousa et al., Phys. Rev. C24, 2245 (1981).

${ }^{11}$ T. Lauritsen et al., Phys. Rev. Lett. 69, 2479 (1992). 


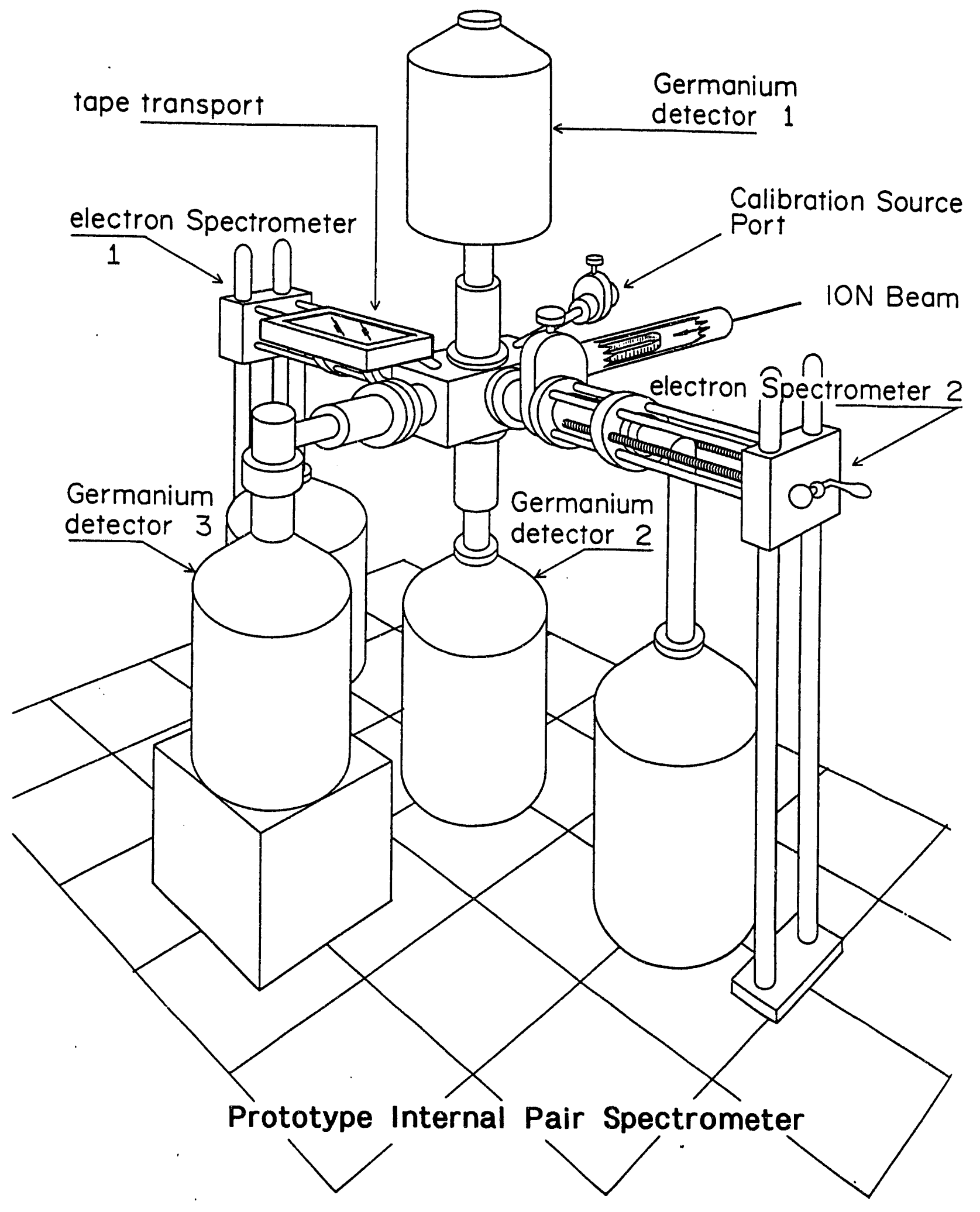


$\frac{5}{\frac{5}{\sigma}}$

品

L 10

$\because \because{ }^{+}$

in

a

$\stackrel{0}{+}$

$\therefore \therefore$ 
\begin{tabular}{l}
$\circ$ \\
\hline \\
8 \\
\hline \\
\hline
\end{tabular}

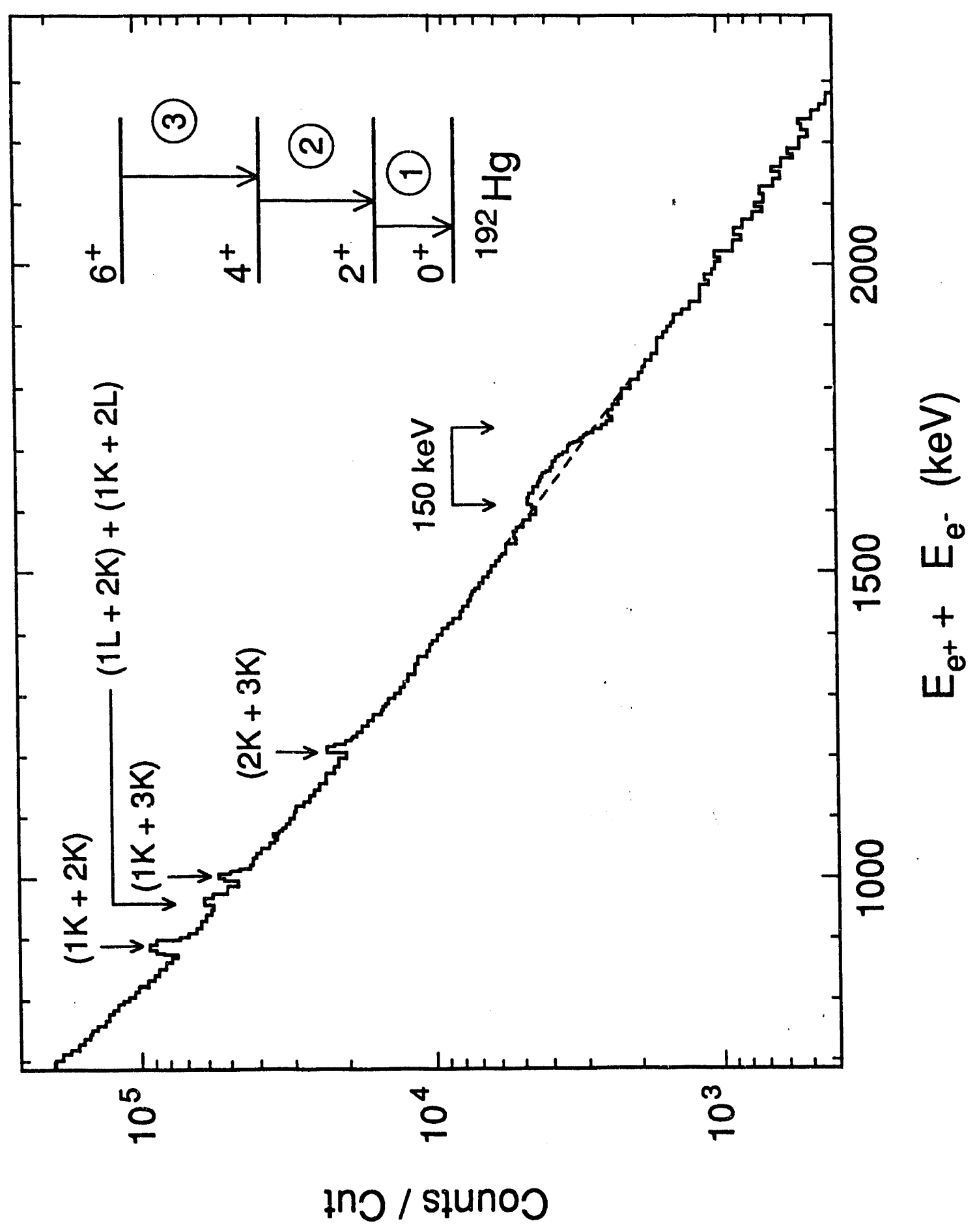




\section{Search for Population of Superdeformed States in ${ }^{194} \mathrm{~Pb}$ using ${ }^{194} \mathrm{Bi} \beta^{+}$ Decay}

A search for the population of superdeformed (SD) states in ${ }^{194} \mathrm{~Pb}$ following the $\beta^{+}$ decay of ${ }^{194} \mathrm{Bi}$ was initiated by the LLNL group and carried out by them at UNISOR with some assistance from the LSU group. The $\beta$ decay of ${ }^{194} \mathrm{Bi}$, with its large $Q_{\beta}$ value and high spins of the decaying isomeric states, provides a favorable opportunity to search for population of known superdeformed states in the daughter nucleus, ${ }^{194} \mathrm{~Pb}$.

Decay of ${ }^{194} \mathrm{Bi} \rightarrow{ }^{194} \mathrm{~Pb}$ offers a better chance to observe the population of known $\mathrm{SD}$ states via $\beta^{+}$decay. The parent ${ }^{194} \mathrm{Bi}$ has a large $\mathrm{Q}_{\beta}(7.98 \mathrm{MeV})$ and three $\beta$ decaying is umeric states with spins of $\left(2^{+}, 3^{+}\right),\left(6^{+}, 7^{+}\right)$and $\left(10^{-}\right)$. The $\left(6^{+}, 7^{+}\right)$isomeric state could populate the spin 6 or 8 superdeformed states; the $\left(10^{-}\right)$isomeric state could populate the spin 10 and possibly 12 superdeformed states (using transitions with higher forbiddeness). The daughter ${ }^{194} \mathrm{~Pb}$ has a known superdeformed band extending lower in spin than any other nucleus in the region. The $169.6-\mathrm{keV}, 8 \rightarrow 6$ transition in ${ }^{194} \mathrm{~Pb}$ exhibits $\sim 50 \%$ of the maximum band intensity. 1 Using second differences in transition energies (dynamic moment-of-inertia) the $6 \rightarrow 4$ transition is deduced by extrapolation to be $\sim 125 \mathrm{keV}$ and would be mostly converted even if the spin 6 level decayed entirely within the band. However, the existence of $\beta^{+}$decay from $\left(6^{+}, 7^{+}\right)$and $\left(10^{-}\right)$isomeric states suggests that the $8 \rightarrow 6$ superdeformed band transition (and possibly the $10 \rightarrow 8$ and even $12 \rightarrow 10$ transitions) might be observed.

The main experimental signature for population of ${ }^{194} \mathrm{~Pb}$ superdeformed states in the $\beta^{+}$decay of ${ }^{194} \mathrm{Bi}$ would be $\gamma$ rays and electrons in coincidence with $\gamma$ rays and electrons of known superdeformed energies. In this experiment, measurements were limited to $\gamma$-e and $\gamma-\gamma$ coincidences. No evidence for the population of superdeformed states was observed. An upper limit for populating the $12^{+}, 10^{+}$, and $8^{+}$levels of the superdeformed band by this $\beta^{+}$decay are $0.034,0.066$, and 0.280 per 100 decays, respectively. 
1E.A. Henry et al., Proceedings of the International Conference on Capture Gamma-Ray Spectroscopy and Related topics, Pacific Grove, CA (1990) 523.

\section{Other Studies}

The lifetime system designed to measure lifetime in ${ }^{186,188} \mathrm{Hg}$, discussed in III A 4 , was also used to make lifetime measurements in the $\mathrm{Z}=50$ region, with the Maryland group and the UNISOR staff taking the lead roles. In one of these studies we measured the lifetime of the $2_{1}^{+}$levels in $118,120 \mathrm{Xe}$ populated through the $\beta+/ \mathrm{EC}$ decay of $118,120 \mathrm{Cs}$, respectively. The major motivation for these measurements was the employment of a different experimental technique to determine the lifetimes for the $2_{1}^{+}$level in these Xe isotopes, and to hopefully resolve the discrepancy in the RDDS lifetime measurements ${ }^{1}$ for the $2_{1}^{+}$level in ${ }^{120} \mathrm{Xe}$.

Samples of $118,120 \mathrm{Cs}$ were produced as recoils from the heavy-ion reaction between a ${ }^{92} \mathrm{Mo}$ target and a $175-\mathrm{MeV}{ }^{32} \mathrm{~S}$ beam. The lifetime system contained a $0.3-\mathrm{cm}$ thick NE111 A plastic scintillator $\Delta \mathrm{E}$ detector for $\beta$, mounted on a Philips XP-2020 photomultiplier tube, and a $1.3-\mathrm{cm}$ thick conical $\mathrm{BaF}_{2}$ crystal mounted on a Philips XP-2020Q for $\gamma$ detection. These detectors were placed face-to-face in vertical positions relative to the beam line. Two Ge detectors were also incorporated into the system, and were placed face-toface in horizontal positions.

The resulting lifetimes were determined using the centroid shift method, where the reference prompt TACs were constructed by getting on the region of the $\mathrm{BaF}_{2} \gamma$-ray spectrum just above the full-energy peak of interest. The use of a background gate as the reference TAC ensures that Compton events from higher $\gamma$ rays will not influence the lifetime measurement. Since there is no dependence of the centroid position on $\gamma$-ray energy in the $\mathrm{BaF}_{2}$ detector for the energy region from 250 to $700 \mathrm{keV}$, as determined from prompt curve calibration measurements using ${ }^{24} \mathrm{Na}$, the difference in the centroid position 
of the full peak and background gates directly yielded lifetimes of $63 \pm 6$ and $64 \pm 4$ ps for the $2_{1}^{+}$levels in ${ }^{118} \mathrm{Xe}$ and ${ }^{120} \mathrm{Xe}$, respectively.

Although the result obtained for the lifetime of the $2_{1}^{+}$level in ${ }^{118} \mathrm{Xe}$ agrees with the adopted lifetime value, ${ }^{1}$ the lifetime for the same level in ${ }^{120} \mathrm{Xe}$ is nearly a factor of two lower than the adopted value. Our result for ${ }^{120} \mathrm{Xe}$ is, however, within the error limit of the most recent RDDS measurement by the Cologne group, ${ }^{2}$ who have reported a lifetime of $75 \pm 7 \mathrm{ps}$ for this $2_{1}^{+}$state.

1S. Raman et ah, Atomic Data Nucl. Data Tables 36, 1 (1987).

${ }^{2}$ A. Dewald et al., Broceedings of XXV Zakopane School of Physics. Singapore, World Scientific, 1990, p. 152. 


\section{Experimental Developments}

\section{A. Picosecond Lifetime Measurement Systems for Levels Populated by Electron Capture and for Levels Decaying by E0 Transitions.}

The measurement of nuclear level lifetimes, which lie in the range of $10^{-10}$ to $10^{-12}$ seconds, can be accomplished using the delayed coincidence method provided the timing resolution of the fast coincidence circuit is sufficient to allow for the distinction between the delayed- an prompt-timing spectra. For sensitivity in the picosecond regime, a fullwidth at half maximum (FWHM) for the prompt-timing spectrum on the order of a few hundred picoseconds is required. This is not attainable using standard semiconductor detectors due to their inherently slow charge collection times.

A system to measure nuclear level lifetimes in the picosecond range was developed recently at the TRISTAN on-line separator facility, 1,2 where they were able to achieve adequate timing resolution with the implementation of $\mathrm{BaF}_{2}$ scintillaiors for the detection of $\gamma$ radiation. Their system is based or the measurement of a fast coincidence between a $\beta$, detected in a thin plastic scintillator detector, and a $\gamma$ observed in $\mathrm{aBaF}_{2}$ detector. Since the energy resolution of a $\mathrm{BaF}_{2}$ detector is rather poor (typically $9 \%$ for the $662-\mathrm{keV}$ transition in ${ }^{137} \mathrm{Cs}$ ) compared to the resolution attainable with a standard semiconductor detector, they employed a second slow coincidence circuit using a Ge $\gamma$-ray detector to isolate the $\gamma$ cascade of interest. The resulting, highly selective, $\beta-\gamma-\gamma$ fast/slow triple coincidence timing circuit allowed one to measure nuclear lifetimes to $\approx 10 \mathrm{ps}$ for $\gamma$-ray energies $\geq 150 \mathrm{keV}$.

One limitation placed on the above system, however, is the requirement of a cascade of $\gamma$ radiations, through the use of a Ge detector, as the transition-selective element. This requirement precludes the measurement of lifetimes for certain nuclear levels; particularly those which decay solely by electric monopole (E0) transitions. Since an E0 transition results in the emission of a conversion electron with no corresponding $\gamma$, these transitions 
would be missed in the system described above. Another limitation is its reliance on the $\beta$ decay process to trigger the fast coincidence system. For nuclei that lie on the neutron deficient side of $\beta$ stability, the electron capture process competes favorably with positron decay, especially in cases where the decay energies are low and $Z$ is large. In the situation where the process of electron capture dominates, there is no emission of a $\beta$ and therefore no trigger for the fast timing circuit.

We have made significant modifications to the original design of the TRISTAN picosecond lifetime system, with the implementation of the $\mathrm{BaF}_{2}$ crystals as $\mathrm{x}$-ray detectors, and $\mathrm{Si}(\mathrm{Li})$ as electron detectors to circumvent the limitations described above. Central to our modification is the replacement of the $\mathrm{Ge} \gamma$ detector with a $\mathrm{Si}(\mathrm{Li})$ electron detector and the use of a $\mathrm{BaF}_{2}$ crystal to detect the $\mathrm{x}$-rays that result from internal conversion of K-shell electrons. Such a system allows one to measure the lifetime of a level which decays only by an E0 transition. A second modification has been the replacement of the thin, plastic $\beta$ scintillation detector with a second $\mathrm{BaF}_{2}$ detector to detect the $\mathrm{x}$-rays that result from the electron capture process. This second modification permits the measurement of nuclear level lifetimes in a system where electron capture is the dominant decay process.

A description of the technique (including sketches) for measurements on $188,186 \mathrm{Hg}$ has been presented in section III A 4, and a complete description will appear in DOE/ER/40159-198.

\footnotetext{
${ }^{1}$ H. Mach, R.L. Gill, and M. Moszynski, Nucl. Inst. Meth. A280, 49 (1989).

${ }^{2}$ M. Moszynski, and H. Mach, Nucl. Inst. Meth. A277, 407 (1989).
} 


\section{B. An Internal Pair Spectrometer for High Energy Conversion Electron Spectroscopy.}

Nuclear transitions can proceed either through the emission of a photon or by one of several alternate processes. Foremost among these is internal conversion (IC) which leads to the emission of an atomic electron with kinetic energy equal to the transition energy minus the binding energy of the atomic shell from which the electron was converted. If the transition energy is greater than $2 \mathrm{~m}_{\mathrm{e}} \mathrm{c}^{2}=1022 \mathrm{keV}$, then an electron positron pair may be created and both emitted from the atom with a shared energy equal to the transition energy minus $1022 \mathrm{keV}$. This is referred to as the internal pair formation process (IPF) and for low $\mathrm{Z}$ and high energy the IPF dominates over IC. ${ }^{1}$ This is shown in the first figure following this section where the ratio of the internal pair probability $\Omega_{\pi}$ to the Kshell internal conversion probability $\Omega_{\mathrm{K}}$ is plotted as a function of energy. Note that for $\mathrm{Z}=40$ and a $6 \mathrm{MeV}$ transition energy, the ratio $\Omega_{\pi} / \Omega_{\mathrm{K}}$ is over 100 , which means that IPF is 100 times more probable than $\mathrm{K}$-shell IC for that case. The variation with multipole order is not strong. ${ }^{2}$

In the process of studying internal pair formation as a tool in the search for the population of superdeformed states in ${ }^{192} \mathrm{Hg}$ from ${ }^{192} \mathrm{Tl} \beta$ decay (section III B 1), we realized the great potential IPF offered in our general study of E0 transitions as well as our work on superdeformation. Thus, we constructed a system that would enable us to place high-resolution, $\mathrm{LN}$-cooled, $\mathrm{Si}(\mathrm{Li})$, electron detectors in close proximity to $\mathrm{Ge}$ detectors to form an internal-pair spectrometer for radioactive decay studies. A schematic of that system is shown in the second figure following this section. The principle of the system is that an event is triggered by the simultaneous detection of electrons $\left(\mathrm{e}^{+}, \mathrm{e}^{-}\right)$in each of the $\mathrm{S}(\mathrm{Li})$ detectors, along with a correlated annihilation photons in each of the Ge detectors which comprise the pair spectrometer. Triggered by that event, the data acquisition electronics interrogates the energy signal of all detectors in the system. 
Alternately, the system can be used for $\mathrm{e}^{--} \mathrm{e}^{-}, \beta-\mathrm{e}^{-}$, or $\alpha-\mathrm{e}^{-}$correlation spectroscopy. One can often do these simultaneously with the proper configuration of electronics. One can then use the Ge detectors which constitute the remainder of the IPF spectrometer as close proximity $\gamma$ detectors and add to the above list with $\mathrm{e}^{-}-\gamma, \beta-\gamma, \alpha-\gamma$, and $\gamma-\gamma$ correlations. With the additional detectors depicted in the figure, many other combinations are possible. The system has just become operational and will be first used in an experiment at ISOLDE/CERN to search for superdeformed states in ${ }^{198} \mathrm{Po}$ and ${ }^{194} \mathrm{~Pb}$ using the decay ${ }^{198} \mathrm{At} \stackrel{\beta}{\longrightarrow} 198 \mathrm{Po} \stackrel{\alpha}{\longrightarrow} 194 \mathrm{~Pb}$.

The system is designed so that the $\mathrm{Si}(\mathrm{Li})$ crystals can be changed quite easily (without disassembling any other components) so that the detector thickness which is appropriate to the specific experiment can be employed. The position of the detectors from the centrally located radioactive source (usually on a tape when on-line to an isotope separator) can be varied from zero to $3.5 \mathrm{~cm}$. This enables one to optimize the spectrometer for the specific application: high efficiency, low angular resolution for searches for E0 transitions, and low efficiency, high angular resolution for multipolarity-discrimination when using it as a multipole meter. A photograph of the cryogenic and electronic components for the $\mathrm{Si}(\mathrm{Li})$ pair is shown in the last figure.

\footnotetext{
${ }^{1}$ P. Schluter, G. Soff, and W. Greiner, Z. Phys. A286, 149 (1978)

2P. Schluter and G. Soff, Atomic Data and Nuclear Data tables 24, 509 (1979).
} 


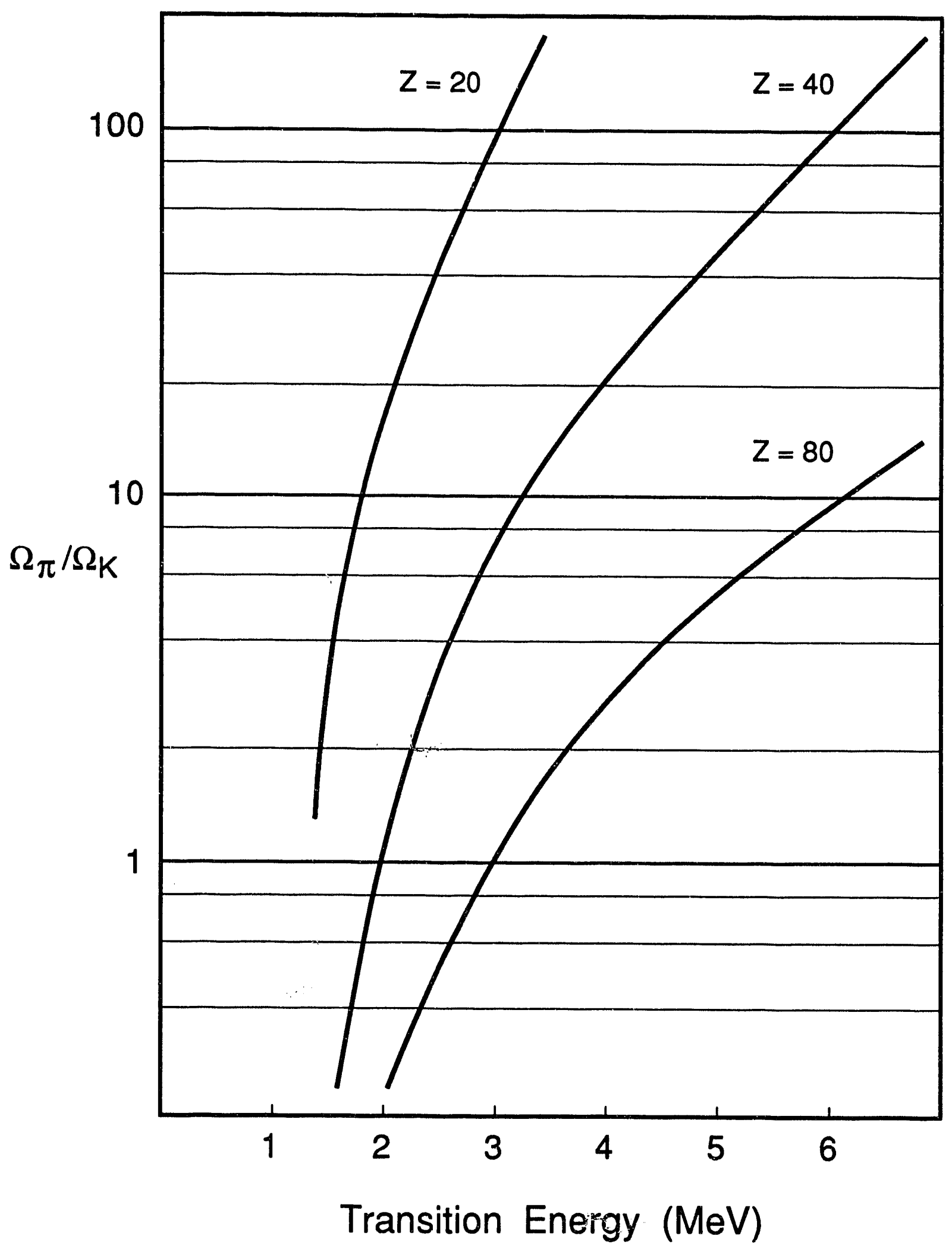



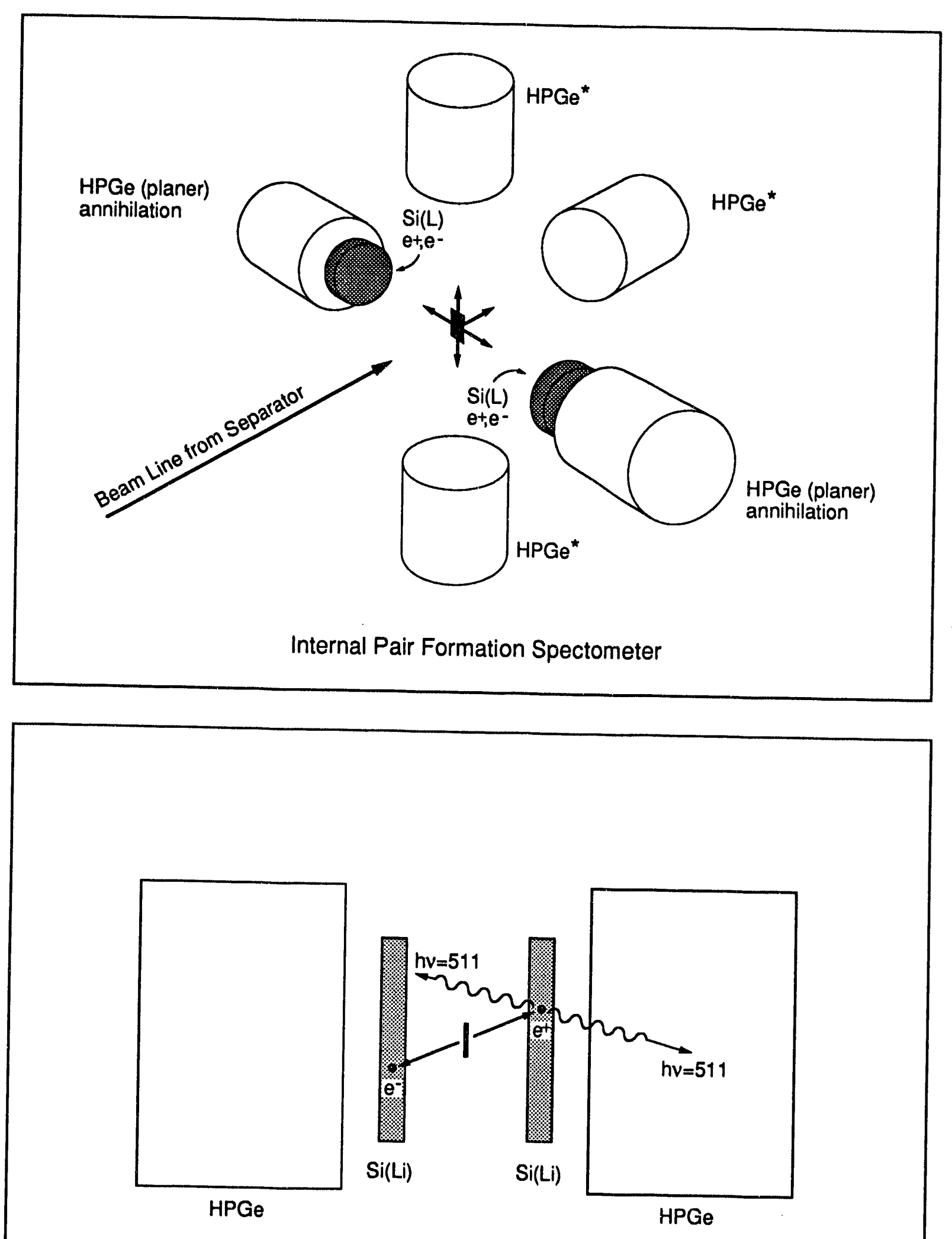

Trigger: Internal Pair Formation Spectrometer 


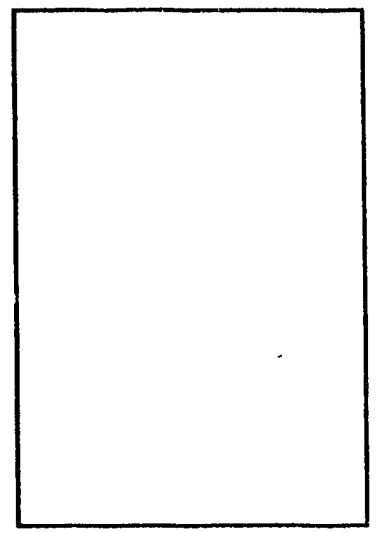

HPGe
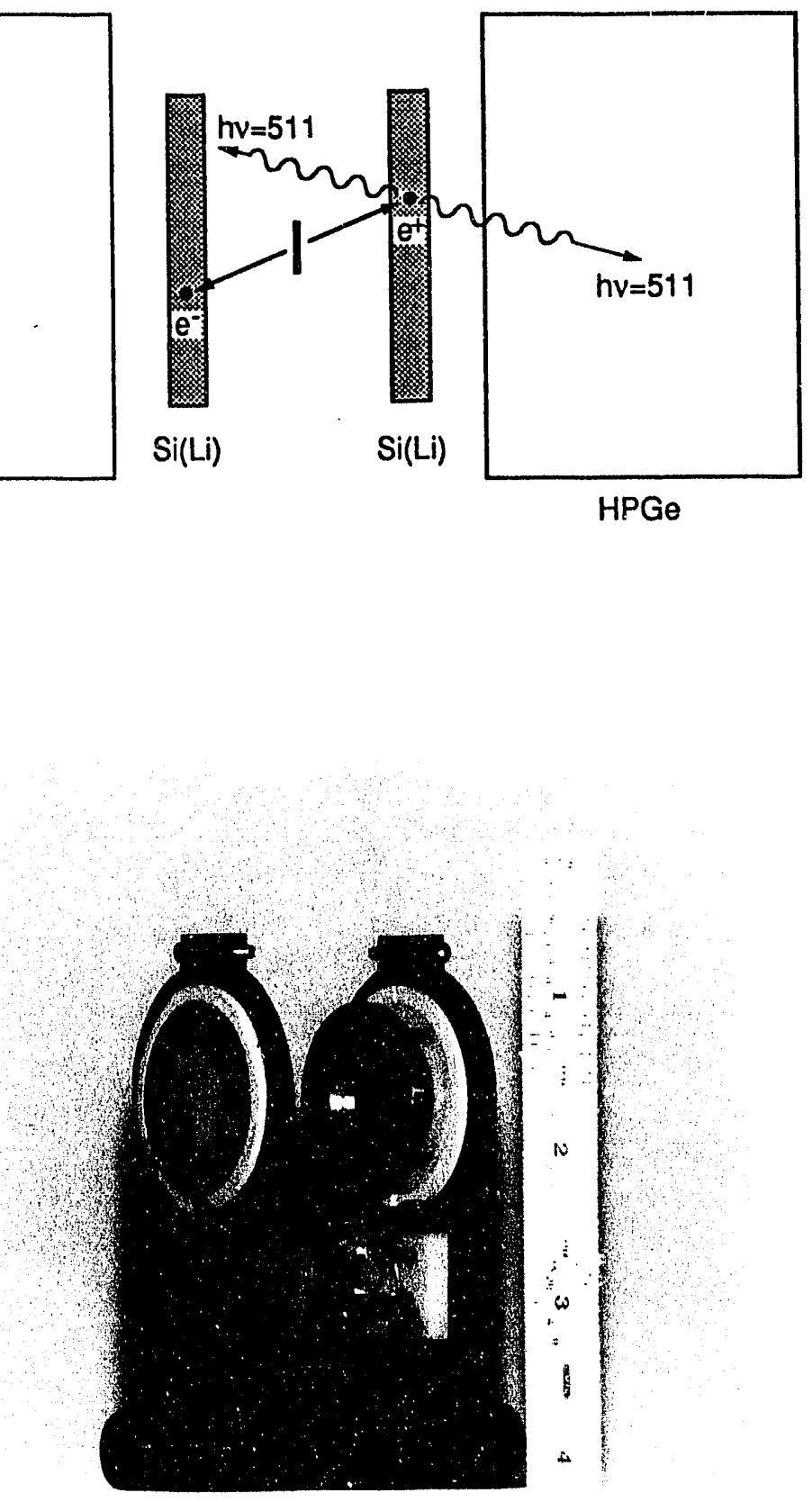

The LN cooled, high-resolution, $\mathrm{Si}(\mathrm{Li})$ detector system for the internal pair formation spectrometer. The HPGe crystals will be placed directly behind each of the $\mathrm{Si}(\mathrm{Li})$ crystals as shown in the sketch. The scale is inches. See the text for more information. 

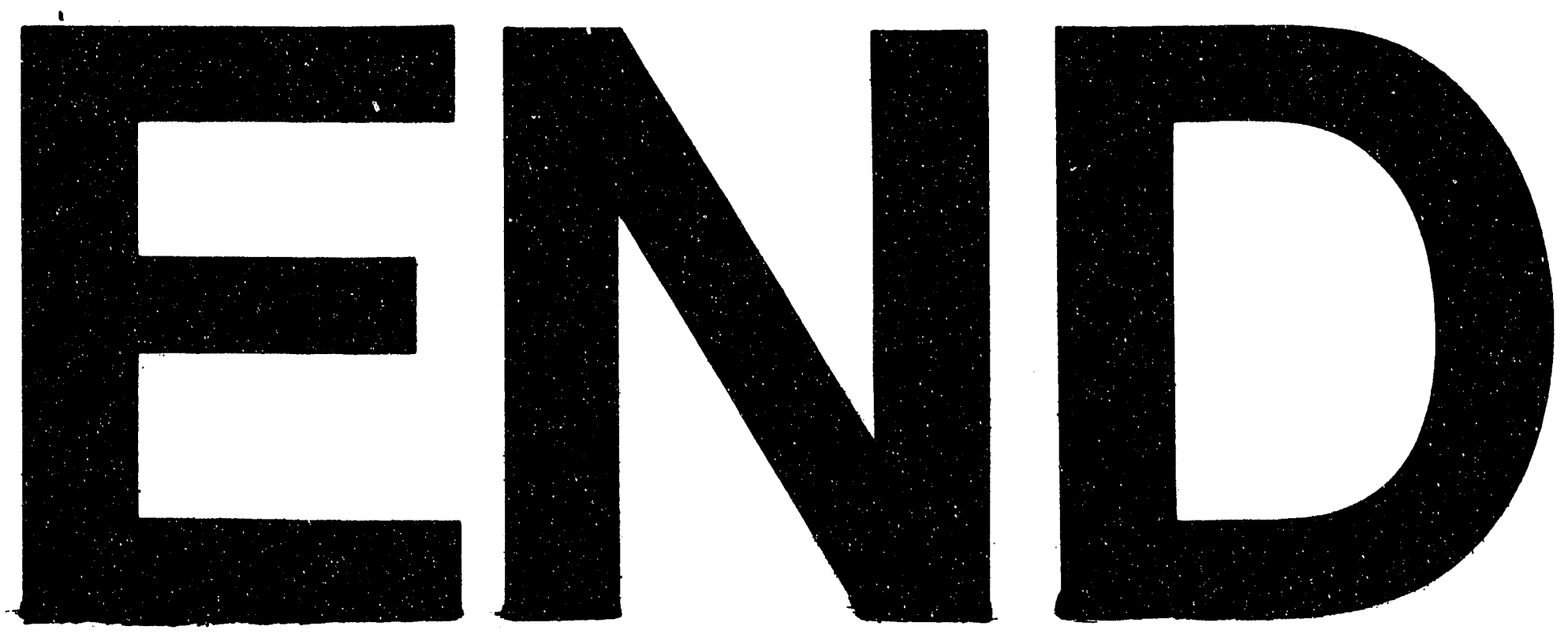

$x$

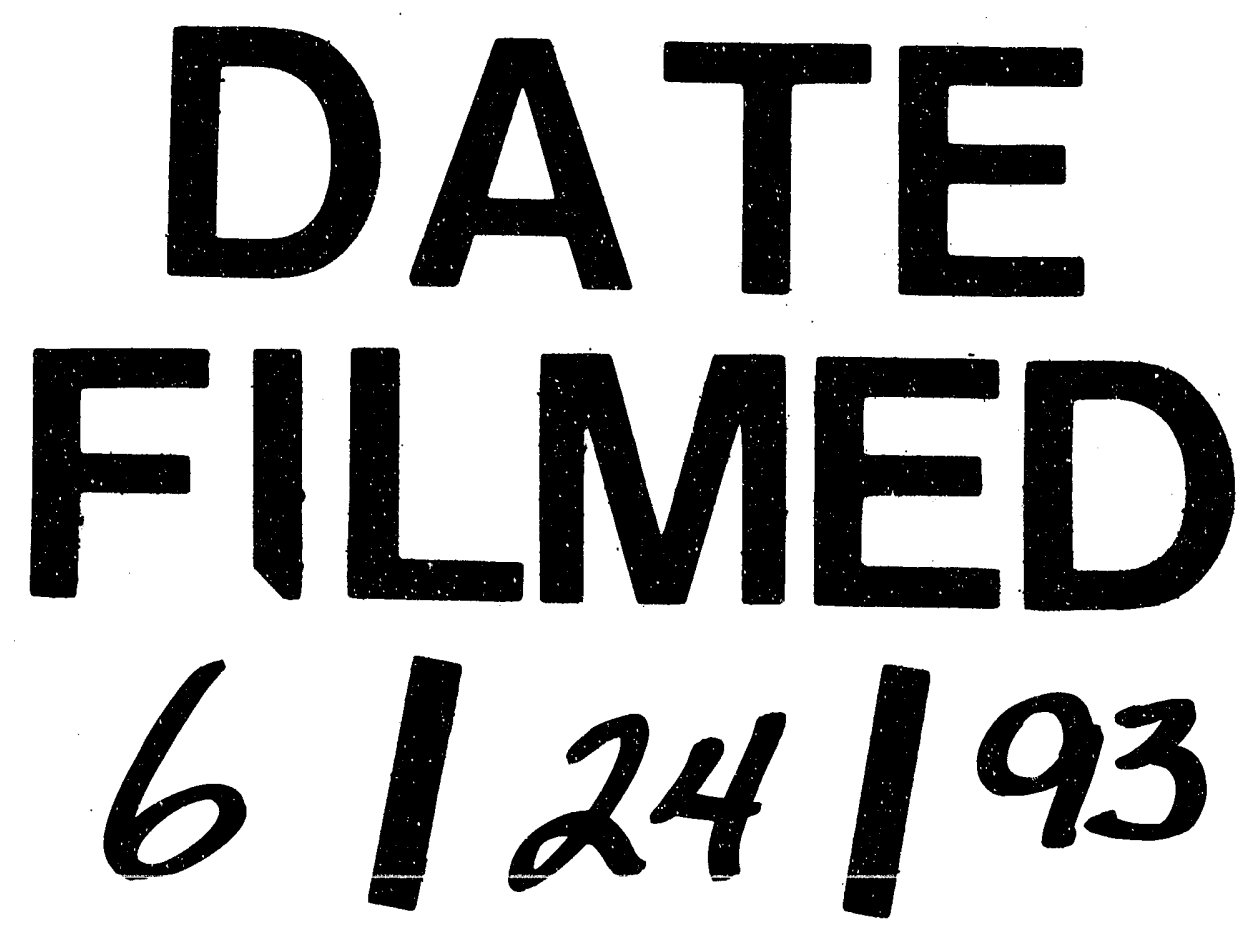


